\title{
Ingolfiellidea (Crustacea, Malacostraca, Amphipoda): a phylogenetic and biogeographic analysis
}

\author{
Ronald Vonk \& Frederick R. Schram \\ Institute for Biodiversity and Ecosystem Dynamics, University of Amsterdam, Mauritskade 57, 1092 AD \\ Amsterdam, The Netherlands
}

Keywords: Ingolfiellidea, phylogeny, biogeography, new genera, paleogeographic maps, bibliography

\begin{abstract}
The suborder Ingolfiellidea currently consists of 39 named species. An historical overview is presented and phylogenetic and biogeographic analyses are made. The result of the phylogenetic analysis suggests the definition of two new genera within an African freshwater group, namely Paraleleupia $\mathrm{n}$. gen. and Proleleupia n. gen. Re-examination of a supposedly Italian reliet species, Metaingolfiella mirabilis, with the aid of SEM techniques reveals a half-fusion of the head region with the first pereionite. The issue of the function of the "eyelobe' is addressed and an explanation presented after examining with SEM such lobes in different species. Furthermore, additional descriptions are given based on the type-material of Metaingolfiella mirabilis, Trogloleleupia eggerti, Trogloleleupia leleupi, Ingolfiella lit-

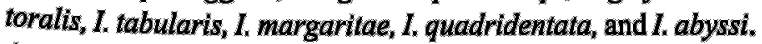
An attempt to relate the geographic distribution and ecological characteristics to the phylogeny of the Ingolfiellidea results in a paleogeographic scenario that points to a freshwater subterranean origin for the group that dates from at least Triassic tîmes.
\end{abstract}

\section{Contents}

Introduction

Methods and material

Character descriptions

Cladìstic analysis

Results

Systematics

Taxonomic diagnoses derived from cladistic analysis $\quad 60$

Ingolfiellidea

Metaingolfiellidae

Ingolfiellidae

Stygobarnardia

Trogloleleupia

Proleleupia
Paraleleupia

Ingolfiella

Additional descriptions

Biogeographic analysis

Discussion

Acknowledgements

References

\section{Introduction}

The ingolfiellidean amphipods are not abundant in regards to the number of species. To date, some 39 species are recognized, a remarkably low number considering the wide-ranging ecological conditions in which they occur. It is also a low number when compared to other family groups of amphipods with partly overlapping habitat requirements such as bogidiellids, with 110 species (Koenemann \& Holsinger, 1999) and crangonyctids (250 species, pers. comm. Koenemann).

The first specimens of Ingolfiellidea were reported by Hansen in 1903. He classified them in a new suborder, a rank they have continued to hold in most publications ( Bousfield \& Shih, 1994; Ruffo \& Vigna Taglianti, 1989; Martin \& Davis, 2001) despite several objections over the years (Dahl, 1977; Bowman \& Abele, 1982; Barnard \& Karaman, 1983). It is a challenge to compare this small group of crustaceans to other larger well-defined groups and try to find comparable habitat preferences and overlapping biogeographic distribution patterns. From consideration of the literature a picture emerges of the uniqueness of ingolfiellideans within the entire crustacean world with regard to their 


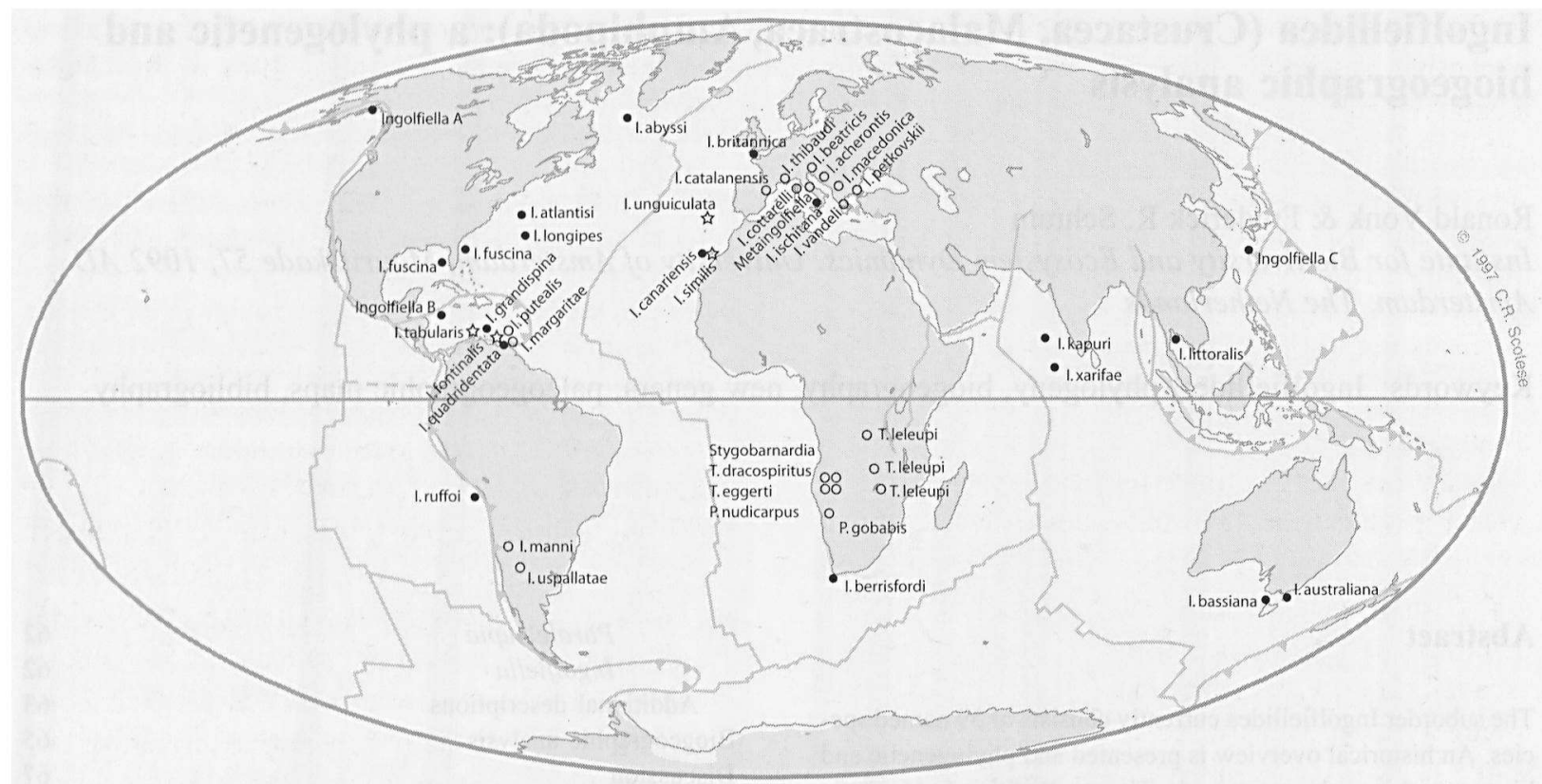

Fig. 1. World map of distribution of Ingolfiellidea. Black dots = marine localities. Open stars $=$ brackish water conditions. Open circles $=$ fresh water localities.

incredibly diverse habitat tolerances. No other small taxon of crustaceans is found in the soft mud of the deep-sea floor, as well as in high mountain freshwater river beds, or in subterranean fresh, brackish and marine interstitial waters of continental ground waters and continental shelves (Fig. 1, map)

The study of the first species of Ingolfiella marked this habitat diversity. Hansen (1903) described two species, Ingolfiella abyssi, from $3521 \mathrm{~m}$. deep sea bottom out of a trawl of 1 litre of mud in the Davis Strait, east of Greenland, and I. littoralis, from coral sands on the shores of Thailand. Several years later another species, I. acherontis (S. Karaman, 1933), was described from a groundwater well in Skopje, Macedonia. The material of $I$. acherontis has been lost and only a few incomplete drawings remain. S. Karaman apparently was not aware of the work by Hansen, 1903. Therefore he described Balcanella acherontis n. gen. n. sp. in a new family Balcanellidae.

After the Second World War expeditions focused more on environments that were difficult to access, and the majority of species of ingolfiellideans were collected in the last half of the twentieth century. A large species was found in cave waters from
Congo, later ranked in a separate genus: Trogloleleupia leleupi (Ruffo, 1951). Compared to the 2.5 $\mathrm{mm}$ specimens for previous taxa this African cave lake species stood out at $14.5 \mathrm{~mm}$ maximum length.

Then more species were discovered in Macedonia: Ingolfiella petkovskii S. Karaman, 1957, and I. macedonica S. Karaman, 1959. S. Karaman characterized their rarity when he stated that he had searched through several thousand samples from ground water and wells. He concluded that Ingolfiella is either very rare or lives in inaccessible biotopes (S. Karaman, 1959).

Meanwhile, another species was found in South America in a new habitat, the coastal ground water in a coarse shingle beach. In the description of $l$. ruffoi Siewing, 1958, Siewing posed a dilemma particularly relevant to the work underlying this publication. He asked whether the large African cave form was ancestral to the smaller marine and freshwater forms, or if it was the other way around.

Another type of habitat was added to the list with the collection of 20 specimens of $I$. britannica Spooner, 1960, from the shell gravel at the sea bottom at 46 meter depth off the south coast of England. Spooner remarked on the true deep sub- 
surface occurrence of these ingolfiellids in contrast with other small malacostracans that more typically inhabit only the first few centimeters of these gravels.

Euryhaline tolerance was revealed within one species with the discovery of $I$. manni Noodt, 1961, taken from both brackish and fresh ground water in Chile. In addition, I. manni was found not only at sea level, but also at $800 \mathrm{~m}$. Later I. uspallatae Noodt, 1965 was described from Argentina in the riverbanks of a floodplain at $2000 \mathrm{~m}$ in the Andes mountains.

In Europe at this time, two freshwater species were reported from the interstices of river alluvia of southern France: 1 . catalanensis Coineau, 1963 and I. thibaudi Coineau, 1968. This marked the discovery of more species where special subsurface habitats were sampled in a conscious effort to uncover new taxa. A large $2.3 \mathrm{~cm}$ ingolfiellid was found in a well in Namibia, first described as Leleupiella eggerti, Ruffo, 1964, later renamed by Ruffo (1974a) as Trogloleleupia eggerti.

From the Indian Ocean I. xarifae Ruffo, 1966 and I. kapuri Coineau \& Rao, 1973 were reported from the Maldives in shallow coral sands, and from the Andaman and Nicobar Islands in intertidal muddy shell debris, respectively.

A second deep-sea species, I. atlantisi Mills, 1967, was collected at more than $4700 \mathrm{~m}$ depth in the North American Basin of the Atlantic Ocean. This species probably occupies the same habitat as $I$. abyssi and was found amidst typical abyssal fauna elements, presumably residing "....in the flocculent and relatively oxidized upper centimeters or two on the surface of the deep-sea ooze." (Mills, 1967).

Back in Europe, an environment equally difficult to access as the deep sea was tapped, namely the 'fossil water' of a $50 \mathrm{~m}$ deep well in Italy. Here the aberrant Metaingolfiella mirabilis Ruffo, 1969 was described, for which a new family was necessary, the Metaingolfiellidae. Later efforts to recapture this rare species were never successful (pers. com. Ruffo). Not surprisingly, the area south and east of Yugoslavia has yielded more specimens of $I$. petkovskii and the new species $I$. vandeli Bou, 1970. They were reported from wells and river sediments on the Greek mainland and the large islands of the Peloponnesus and Euboea.

Another discovery occurred in the littoral sands of Table Bay, Cape Town: I. berrisfordi Ruffo, 1974.
From the same environment, but a little deeper at $8 \mathrm{~m}$ below the surface in the Gulf of Naples, Italy, Schiecke (1976) described $I$. ischitana. Stock named 6 species from islands off the coast of Venezuela. These species are: I. (Gevgeliella) putealis Stock, 1976, in a slightly brackish well on Bonaire (Dutch Antilles); I. (Gevgeliella) fontinalis Stock, 1977, from a spring on Bonaire; I. (Gevgeliella) tabularis Stock, 1977, from marine sands situated below a cave entrance on Bonaire (also recorded on Curacao); I. (Hansenliella?)quadridentata Stock, 1979, from coarse coral sand of a submarine flat, Curacao; I. (Trianguliella?) grandispina Stock, 1979, pumped from brackish ground water in gravel at a cave entrance; I. (Gevgeliella) margaritae Stock, 1979, from a capped freshwater well used for drinking water on Isla de Margarita (Venezuela). These southern Caribbean species were sampled either by diving in shallow coastal water, or pumped up from beach interstitia and oligohaline water reservoirs more inland. In addition, animals occurred in wells and small cave chambers with brackish water or water with frequently and strongly fluctuating salinities.

Stock utilized subgeneric names, but the splitting of the genus Ingolfiella into smaller units had already begun with that earlier discovery of Ingolfiella (Balcanella) acherontis Karaman, 1933. Nevertheless, Karaman's original effort did not prove very useful due to subsequent workers' lack of male or female specimens in cases where both sexes were needed to make critical distinctions. Consequently, new species were difficult to incorporate into the existing system.

Ruffo (1985) described another large ingolfiellid from Namibia's freshwater reservoirs, Stygobarnardia caprellinoides. The most striking aspect of this animal was the resemblance of the form of the cephalon to that of the Italian Metaingolfiella. In Metaingolfiella the fusion of the first segment (pereionite) with the cephalon was described as fully complete (although we have discovered after SEM investigation that this appears not to be the case), while in Stygobarnardia the head form with a typically small cephalon could be interpreted as in a partial stage of the fusion.

One of the larger Canary Islands facing the coast of West Africa, Fuerteventura, yielded Ingolfiella 
similis Rondé-Broekhuizen \& Stock, 1987, from an oligohaline freshwater well. Ingolfiella fuscina Dojiri \& Sieg, 1987, was found in the Gulf of Mexico and off the coast of South Carolina in box core and grab samples ranging in depth from $17-151 \mathrm{~m}$. This was the first time a species from the bottom of the sea was reported over a large area. On Bermuda, I. longipes Stock, Sket \& Iliffe, 1987 was collected in a brackish water cave pool. More large ingolfiellids came from Namibia: Trogloleleupia dracospiritus Griffiths, 1989 and T. gobabis Griffiths, 1989, were found in cave lakes, $350 \mathrm{~km}$ apart from each other.

The Southwest Pacific yielded no ingolfiellids until Lowry \& Poore (1989) described I. australiana and $I$. bassiana from the Bass Strait at, respectively, $85 \mathrm{~m}$ depth in sandy shell, and $121 \mathrm{~m}$ at another locality in the strait. A cave on a small offshore island of Sardinia, Italy, brought to light $I$. cottarellii Ruffo \& Vigna-Taglianti, 1989 from a freshwater pool. The most recent of the large, cave dwelling, African ingolfielids is Trogloleleupia nudicarpus Griffiths, 1991 from subterranean waters in western Namibia. It was found crawling on stones in shallow water in a small pool $60 \mathrm{~m}$ below ground surface.

I. canariensis Vonk \& Sánchez, 1991, was collected with a Bou-Rouch biophreatic pump on several beaches along the north coast of Tenerife, Canary Islands, and in bottom debris of an anchialine cave on El Hierro, another island in the geologically younger part of the Canary group. From the island of Madeira, some $700 \mathrm{~km}$ to the north, $I$. unguiculata Stock, 1992 occurs in the coarse sand bottom of an anchialine lagoon. In Slovenia, $I$. beatricis Ruffo \& Vonk, 2001 was described from a single specimen caught in a feeble flowing cave stream with a hand net.

Of course, more species will be discovered, and we must wait to see how far the ecological tolerance and biogeographical spread of this group of amphipods can be stretched. Already there are reports of discoveries in fresh- and brackish water of Japan (Shokita, 1992) and in marine sediments of the Prince William Sound, Alaska, and the Virgin Islands, Caribbean (Cadien, pers. comm.) that are yet to be confirmed.

From the above it is clear that almost all previ- ous work on the Ingolfiellidea has concentrated on alpha-taxonomy. To remedy this situation we undertook the following:

a. Performed a cladistic analysis of phylogenetic relationships within the Ingolfiellidea based on a comprehensive character matrix.

b. Restudied type material of Metaingolfiella $\mathrm{mi}$ rabilis, Trogloleleupia eggerti, $T$. leleupi, Ingolfiella abyssi, I. littoralis, I tabularis, I* quadridentata, and $I$. margaritae to add more details to former descriptions.

c. Compared the cephalic lobes of Ingolfiella putealis and $I$. ischitana, using SEM photography, to lend insight into the anatomical and functional role this structure plays.

d. Re-examined the type material of Metaingolfiella mirabilis to determine the degree of fusion between the head and the first pereionite.

e. Performed a biogeographic analysis with the results of the cladistic analysis and explored palaeobiogeographic patterns and the timing of evolutionary events in the deep history of ingolfiellideans.

\section{Methods and material}

We employed 43 characters to analyze patterns of relationships throughout the Ingolfiellidea. Some 30 characters are multistate, while 13 features are binary. Following here is a list of the characters employed and an explanation of the several alternative states we have used in constructing a matrix (Table I). Given the 'reduced', worm-like body plan of these animals our 43 characters essentially covered all aspects of the recognizable anatomy, so there has been no emphasis of one aspect of morphology over another. The characters we used are as follows.

\section{Character descriptions}

1. Ocular (cephalic) lobes

state $0=$ developed

state $1=$ reduced

state $2=$ absent

In one of the out-group taxa chosen, Mictocaris 
halope, this character is termed the eyestalk. Its location is not between antenna 1 and antenna 2 on the front margin of the cephalon, as in the Ingolfiellidea, but is rather located a little higher, flanking the peduncle of antenna 1. Still we consider this possible remnant of a stalk in Mictocaris as an homologous feature with the typical ingolfiellidean cephalic lobe, simply because no other function can be ascribed with certainty to this lobe at the moment. Lowry and Poore (1989) observed that three peracaridan orders have representatives with eyestalks or remnants of stalks, i.e., the mysidaceans, the spelaeogriphaceans, and the mictaceans. However, they conclude that the typical position of the reduced stalks, which are often in the form of scales or pointed lobes, lies at the base of the first antenna and at the rostrum. This is different from that seen in the Ingolfiellidea, where, as noted, the lobes reside between the first and second antennae. Therefore, they do not regard these features as homologous and thus not of subordinal importance.

However, spelaeogriphaceans and mictaceans do not have the lateral compressed head of ingolfiellideans (and of most amphipods) and the position of the lobes could easily have shifted ventrally when that would be the case. We have made SEM photographs of two ingolfiellid species, Ingolfiella ischitana (Fig. 2a) and I. putealis (Fig. 3a,b), in which the difference between the developed state of the lobe in the former (Fig. 2, b-e) and the reduced state (Fig. 3, a-c, e, f) in the latter is clearly visible. In both cases, there is a neat fit of this lobe between the bases of the first and second antennae, and this suggests that the original function (eyestalk) has been replaced by a new function. The lobes close off the otherwise open space between the antennae to mud particles. Thus the appressed lobes and the rostrum form a tight seal around the protruding antennal peduncles, preventing fine granular material from fouling the head region.

\section{Antenna 1, flagellum}

state $0=$ longer than basal peduncular segment state $1=$ medium length, more than half of basal peduncular segment

state $\mathbf{2}=$ short, less than half of basal peduncular segment

The low number of segments (4) on the antennal flagellum is a consistent character throughout the Ingolfiellidae and as such not informative towards distinguishing between species or species groups within the family. However, the length of the flagellum as a whole does vary in a few cases, and the differences were scored. Out-groups have more segments, as is common in most peracaridans, and thus bear a relatively long antennal flagellum (state 0 ). Absolute measurements of the flagellum depend on the size of the individual. With a ratio character like this it is often difficult to divide continuous distributions into integral states. Still an effort is made to distinguish between longer and shorter antennae as our goal was to score as much character differentiation as possible.

\section{Antenna 1 , accessory flagellum \\ state $0=$ four segments \\ state $1=$ three segments \\ state 2 = twio segments}

The accessory flagellum is positioned on the inner side of the flagellum (Fig. 3d, 5k, 7c) and could be called the "inner" flagellum, if we want to keep the terminology that would be comparable to early, fossil finds of diverse crustaceans. The positional homology is important here for in Mictocaris the outer flagellum has eight segments and the inner has four segments. We might ask if the accessory flagellum in amphipods is comparable to the outer or inner flagellum of Mictocaris?

"The primitive biramous origin is retained in the form of a small accessory flagellum that arises from the end of the peduncle," (Lincoln, 1979, p.16). In Mictocaris, the eight-segmented "outer" flagellum bears the aesthetascs, which would suggest the foursegmented "inner" flagellum, which lacks aesthetascs, is equivalent to the accessory flagella in amphipods, also lacking aesthetascs.

\section{Mandibular palp \\ state $0=$ present \\ state $1=$ vestigial \\ state $\mathbf{2}=$ absent}

The mandibular palp is lacking in the Ingolfiellidea. This implies that the palp is not necessary towards either securing and moving larger food particles to the mouth and the molars, or in cleaning and grooming, as is typically the case for the larger palps seen 


\begin{tabular}{|c|c|c|c|c|c|c|c|c|c|c|c|c|c|c|c|c|c|c|c|c|c|c|c|c|c|c|c|c|c|c|c|c|c|c|c|c|}
\hline$\stackrel{?}{\sim}$ & 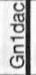 & & - & - & - & - & - & $\sim$ & $\sim$ & & & & ผ & $\nabla$ & $\sim$ & & & $\nabla$ & $\nabla$ & N & & $\approx$ & & . & $\sim$ & $N$ & & & $\sim \sim$ & $\sim$ & $\sim$ & & $\checkmark \sim$ & $\theta$ & & $\nabla$ \\
\hline 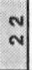 & & 0 & - & - & - & N & $\sim$ & $\sim$ & $\sim$ & & & N & $\sim$ & $\sim$ & N & & & $\sim$ & $\sim$ & $N$ & $\sim$ & & & & $\sim$ & $N$ & & & & $\sim$ & N & & $\sim \sim$ & $\sim$ & & N \\
\hline 5 & & 0 & 0 & 0 & 0 & & & - & $\sim$ & $\sim$ & - & 0 & 0 & 0 & & o & 0 & 0 & 0 & 0 & & 0 & & & 0 & 0 & & & 00 & 0 & 0 & & 0 & 0 & & 0 \\
\hline i & 总 & o & - & - & - & & 0 & 이 & 0 & & 인 & & 0 & 0 & & - & & 0 & o & 0 & - & & & & 0 & 0 & 0 & 00 & 00 & 0 & & & 0 & 0 & & - \\
\hline m & & 0 & 0 & - & - & N & $N$ & - & 0. & - & $\sim$ & & $\stackrel{N}{=}$ & - & a. & - & - & $\sim$ & 0 & - & 0 & a. &.- & $-a$ & - & $a$ & N & & - & - & a. & & $a$ & a. & a. & N \\
\hline$\stackrel{\infty}{\infty}$ & & $\circ$ & 0 & 0 & & - & 0 & 이에 & 0 & 0 & 0 & 0 & 0 & & 0 & 0 & 인 & 0 & 0 & 0 & 0 & & & 00 & 0 & 0 & 0 & & 00 & 0 & 0 & $\circ 0$ & 0 & 0 & & 0 \\
\hline \pm & & & - & $\sim$ & & 0 & m) & $\nabla$ & 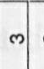 & m & m) & $m$ & 0 & & +0 & m & 4 & - & - & $m$ & $\theta$ & A. &.- & $-\sim$ & $\sim$ & $\sim$ & N & & $v-$ & - & $\nabla$ & $\sim \approx$ & 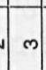 & $\sim$ & & N \\
\hline$\stackrel{0}{-}$ & & & - & - & - & 0 & - & - & - & - & - & $\tau$ & - & of & - & - & - & - & - & - & - & - & $-\tau$ & -1 & - & - & - & & -- & 0 & $\tau$ & 0 - & $-1-$ & - & a. & - \\
\hline is & & & 0 & 0 & 인 & 0 & - & - & - & - & - & - & - & - & - & - & - & - & - & - & - & & & $-\gamma$ & - & - & - & & -- & - & - & - & $-1-$ & - & 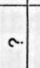 & - \\
\hline 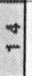 & $\begin{array}{l}\text { 웜 } \\
\text { 일 }\end{array}$ & 0 & - & - & - & 0 & 0 & 이 & 0 & 0 & 0 & 0 & 0 & 0 & - & 0 & o & - & 0 & 0 & - & & & 00 & 0 & 0 & 0 & & $0 \Omega$ & 0 & 0 & $\circ 0$ & 0 & 0 & & - \\
\hline 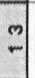 & $\begin{array}{l}\text { व } \\
0 \\
0 \\
0 \\
\frac{x}{2}\end{array}$ & - & - & - & - & 0 & - & - & - & - & - & - & - & - & - & - & - & - & - & - & - & & -7 & -- & - & - & - & - & -- & - & - & - & - & - & $\therefore$ & - \\
\hline$\stackrel{9}{7}$ & $\underset{x}{x}$ & 0 & - & - & - & - & - & - & $\cong$ & $\sim$ & ल & - & - & a. & $\frac{m}{\sim}$. & - & - & $m$ & & $\stackrel{m}{\sim}$ & - & & $\sim$ & $=\frac{m}{c}$ & & a. & $\sim$ & ๙ & $m$ & $\frac{m}{n}$ & $\stackrel{m}{\sim}$ & m & $v m$ & a. & & m \\
\hline : & & & - & - & - & 0 & - & 이 & 0 & - & 0 & - & - & - & 0 & & $\sim$ & $\sim$ & - & - & - & 0 & & N - & - & N. & м & - & $\sim \sim$ & $\sim$ & - & N & $1 m$ & $\sim$ & & $\sim$ \\
\hline$\stackrel{0}{-}$ & & & 0 & 0 & 0 & 0 & - & - & - & - & - & 0 & 0 & 0 & & 0 & 0 & - & - & 0 & & & - & $\tau$ & & a. & & 0. & -0 & - & - & 0 & $\sim$ & - & a. & - \\
\hline a & $\frac{0}{x}$ & & $\sim$ & - & $m$ & $\sim$ & $\theta$ & 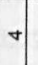 & is . & $\nabla$ & ๑ & $\nabla$ & $\nabla$ & + & ـ & 寸 & 寸 & 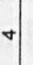 & $\theta$ & $\nabla$ & & v & $\forall$ & $\theta \theta$ & & $a$ & $\theta$ & $\theta$ & $\begin{array}{lll}4 & 0\end{array}$ & $\theta$ & $\nabla$ & $\forall 10$ & $\begin{array}{lll}0 & 0\end{array}$ & $\forall$ & & $\infty$ \\
\hline$\infty$ & $\begin{array}{l}\frac{a}{2} \\
\frac{1}{x} \\
\frac{x}{2}\end{array}$ & 0 & & - & $\stackrel{\sim}{\simeq}$ & $\sim$ & - & $\stackrel{\simeq}{=}$ & $\sim$ & $\sim$ & $\sim$ & $\sim$ & $\cong$ & $\stackrel{\sim}{=}$ & $\cong$ & $\stackrel{\sim}{\approx}$ & - & $\stackrel{N}{-}$ & $\cong$ & $\sim$ & 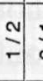 & $\overline{0}$ & ৯ & $N \infty$ & & $a$ & $\sim$ & $\sim \cong$ & & $\sim$ & $\stackrel{N}{=}$ & \begin{tabular}{c|c}
$c$ \\
$\vdots$ \\
$\vdots$
\end{tabular} & $\cong$ & & $\sim$ & - \\
\hline r & 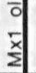 & & 0 & - & - & - & - & - & - & - & 0 & - & - & - & - & - & - & o & - & 0 & - & - & & 0 & - & a. & - & 0 & -- & 0 & - & 0 & 0 & - & & - \\
\hline$\bullet$ & $\begin{array}{l}= \\
\bar{x} \\
\bar{x}\end{array}$ & 0 & N & - & เ & $\theta$ & - & - & m & ल) & - & $\sim$ & $N$ & $\sim$ & m. & $\forall$ & $\stackrel{m}{N}$ & ल) & $m$ & $\theta$ & N & & & $\theta t$ & & a. & & & $\theta+$ & + & $N$ & & $\theta$ & & & $\infty$ \\
\hline 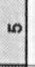 & 형 & 0 & & 0 & 0 & - & - & - & - & - & - & - & - & - & - & - & - & - & - & - & - & - &.- & - & - & - & - & & -- & - & - & -1 & - & - & & - \\
\hline . & 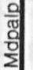 & 0 & & 0 & 0 & N & - & $\sim$ & N & ๙ & ๙ & $\sim$ & ก & s & N & $\sim$ & & N & $\sim$ & N & s & $\sim$ & & N & & N & $\sim$ & & $\mathrm{N} \sim$ & N & $\sim$ & $\sim \approx$ & $\checkmark \sim$ & $\sim$ & & $\sim$ \\
\hline 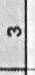 & $\frac{\pi}{4}$ & 0 & $\sim$ & $\sim$ & $\sim$ & - & - & - & - & - & - & - & - & $\sim$ & $\sim$ & - & - & - & - & - & $\tau$ & $\tau$ & $-r$ & - & - & - & - & - & $-\sim$ & - & - & $-\infty$ & $v-$ & - & & - \\
\hline . & $\bar{\square}$ & 0 & & 0 & 0 & & - & $\sim$ & - & - & $\stackrel{\simeq}{=}$ & & - & - & - & - & - & - & - & - & - & & -1 & $-a$ & - & - & - & & -- & - & - & - & 10 & - & & - \\
\hline & & & & & & & & & & & & & & & & & & & & & & & & & & & & & 0 & & & * & $-N$ & & & 0 \\
\hline
\end{tabular}

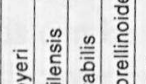

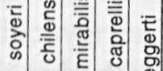

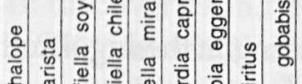

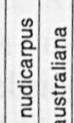

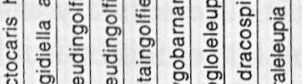

흔 형

$-$

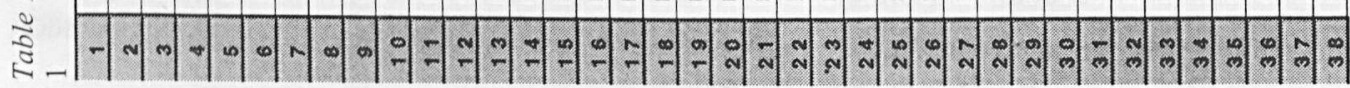

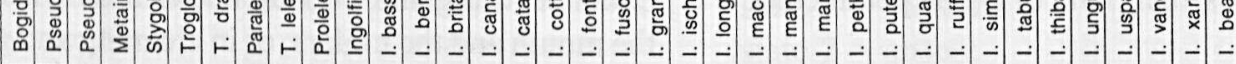




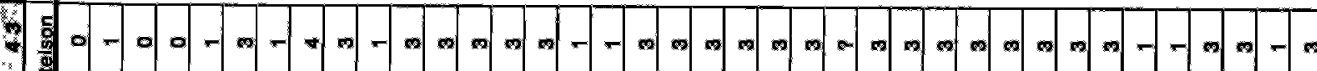

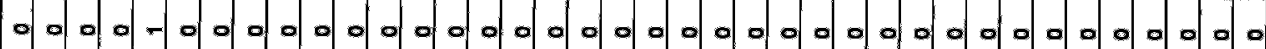
0.

용. $-7-7$

$\$$

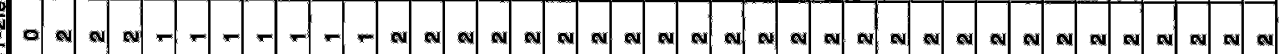

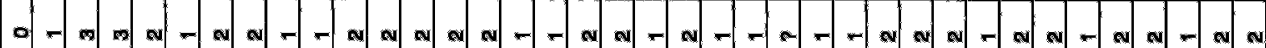

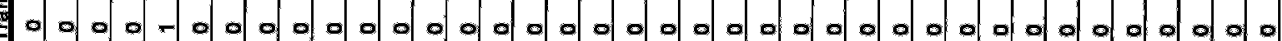

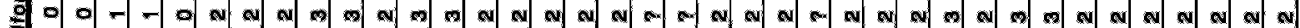

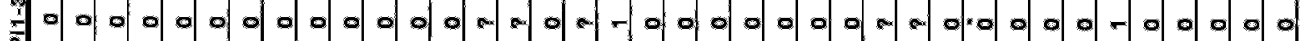

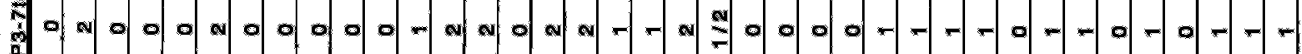

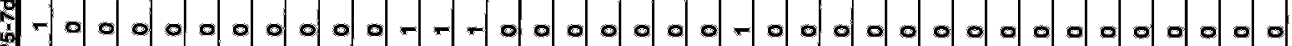

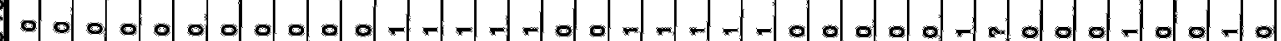

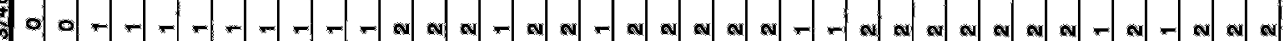
a

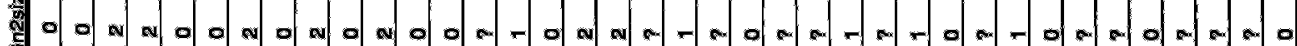

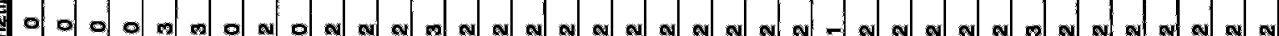

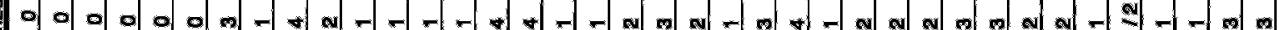

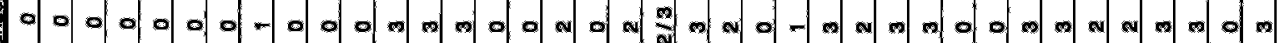

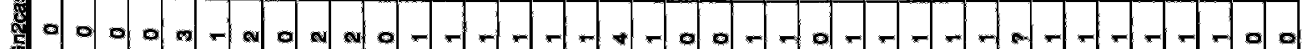

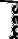

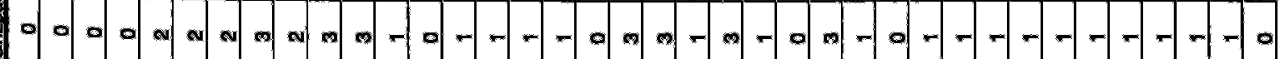
(1)

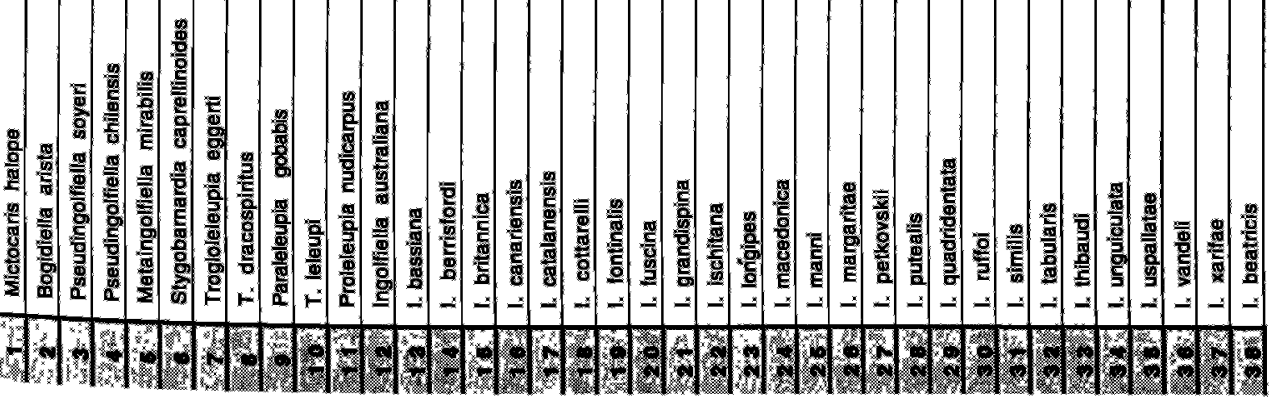


in malacostracan crustaceans. Fine food particles make up the diet in this line of reasoning. One genus in the Ingolfiellidae, Stygobarnardia Ruffo 1985, possesses a rudiment of the mandibular palp and is scored as vestigial (1).

This reduction and/or complete loss of a mandibular palp occurred in many groups of crustaceans (Richter and Scholtz, 2001) and shows a great variability within families and genera of Amphipoda. For instance, a mandibular palp may be present or absent within the Ampithoidae and Hadziidae, or it may vary in length as in Metacrangonyx. Even so, this phylogenetically uninformative character is retained here to emphasize the special situation in Stygobarnardia and to be available for use with possible finds of new taxa.

\section{Molar process size}

state $0=$ well-developed lobe

state $1=$ vestigial peg or spine

All Ingolfiellidea share the reduced state (Figs. 5c, $61, n$, arrows). In combination with the absence of mandibular palps, this feature perhaps points to a lack of need for structures to chew up large particles of food.

\section{Maxilla 1, inner lobe setae (Figs. $5 \mathrm{a}, 6 \mathrm{j}, \mathrm{m}$ )}

state $0=$ numerous

state $1=$ four or more

state $2=$ three

state $3=$ two

state $4=$ one

state $\mathbf{5}=$ none

This character is constant within those taxa wherein populations were used for species descriptions, thus it seems significant at least for differentiation of species. This feature is often mentioned only in the "remarks' section of species descriptions as one that differs between species. The condition in which the lobe is fringed with numerous hairs seems to point to an original state. Decidedly more generalized forms, such as Euphausiacea, have many setae on the inner lobe of the maxillule ( Maas \& Waloszek, 2001)

7. Maxilla 1 outer lobe, inner seta (Figs. $5 \mathrm{a}, 6 \mathrm{j}, \mathrm{m}$ ) state $0=$ simple

state $1=$ bifid state $\mathbf{2}=$ dentate

When comparing the tips of the robust apical setae on the distal margin of the outer lobe of maxilla 1 , clear differences were noticed between several species. In most species the inner seta stands apart from the others and is implanted on the lateral/submarginal, inner side of the plate. Often it is clearly dentate with a little comb, at other times it is simple.

8. Maxilla 1 outer lobe, outer setae (Figs. 5a, 6j, $\mathrm{m})$

$$
\begin{aligned}
& \text { state } 0=\text { simple } \\
& \text { state } 1=\text { bifid } \\
& \text { state } 2=\text { dentate }
\end{aligned}
$$

"Simple" setae are smooth, spiniform setae without hooks. In case more states are present, a multistate score is used $(0 / 1$ or $0 / 1 / 2)$. Comparison with the out-group Mictocaris halope seems to indicate that an earlier condition might have resembled an undifferentiated tuft of soft setae (Bowman \& Iliffe, 1985)

9. Maxilla 1, outer lobe, setae orientation

state $0=$ continuous row

state $1=7+$ additional inner seta

state $2=7$

state $3=6+$ additional inner seta

state $4=6$ (Fig. 5a)

state $5=5$

The setae on the distal margin of the outer plate of the maxilla 1 can differ in number. The additional seta often sits a little sideways on the inner margin of the lobe. We have no preconceived notion as to what might be the derived situation. We suspect, however, that the most reduced situation (5 setae) reflects the derived state here.

\section{Maxilla 1, palp size} state $\mathbf{0}=$ larger than outer lobe state $1=$ subequal to outer lobe state $\mathbf{2}=$ smaller than outer lobe The need for elaborate handling of larger food items may require a long palp ( 0 ) as opposed to a short palp (2). Assumption of the interstitial mode of life, generally supposed to be a secondary habitat choice in the evolution of Amphipoda, may have induced the loss of importance for a maxillular palp. 

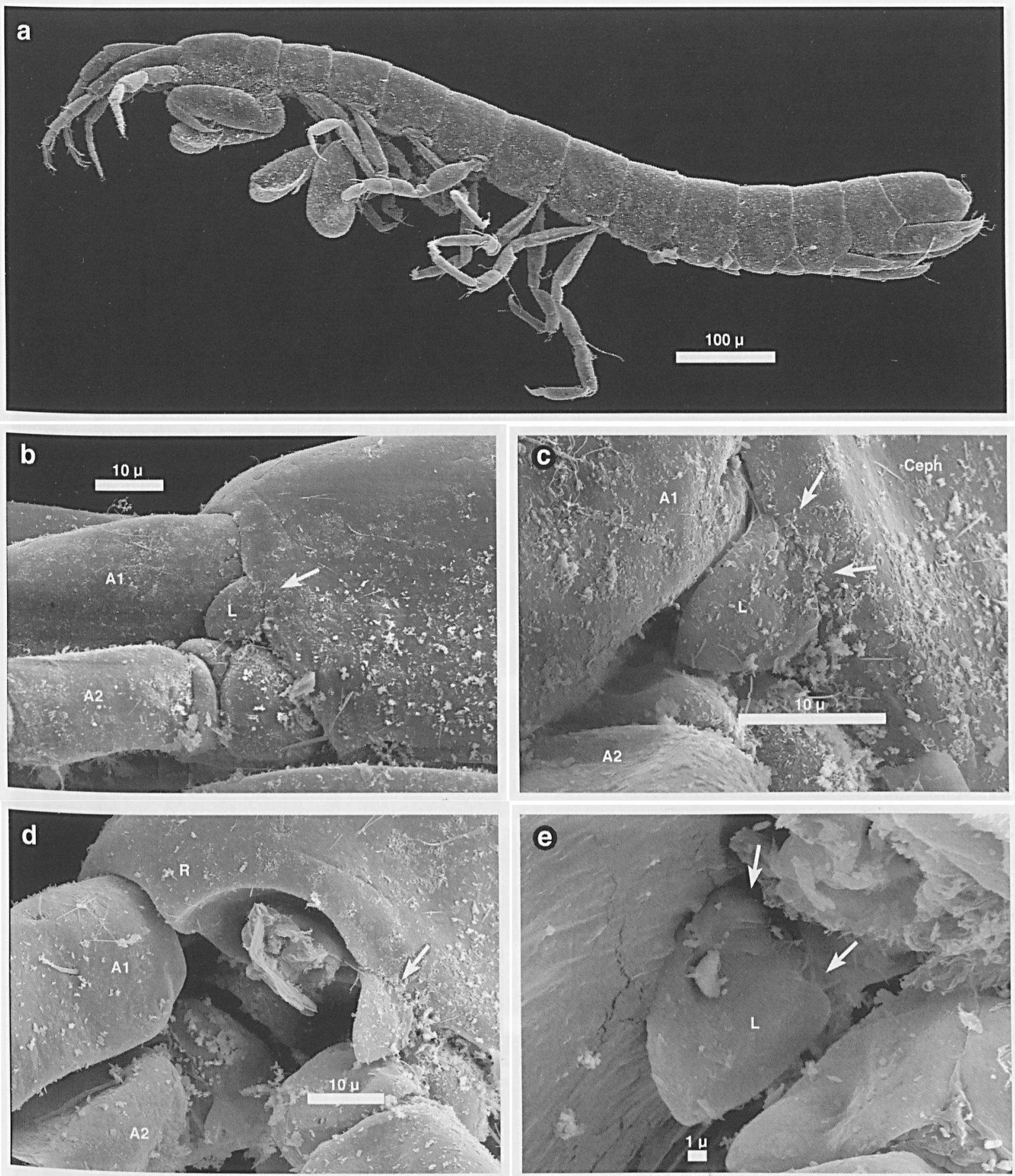

Fig. 2. Ingolfiella' ischitana, paratype. SEM photographs of: $\mathrm{a}$, habitus; $\mathrm{b}-\mathrm{c}$, lateral view of a well-developed cephalic frontal margin lobe; $d-e$, lobe seen from outside and inside (removal of first antenna), cuticular "hinge" visible (e, right arrow). 

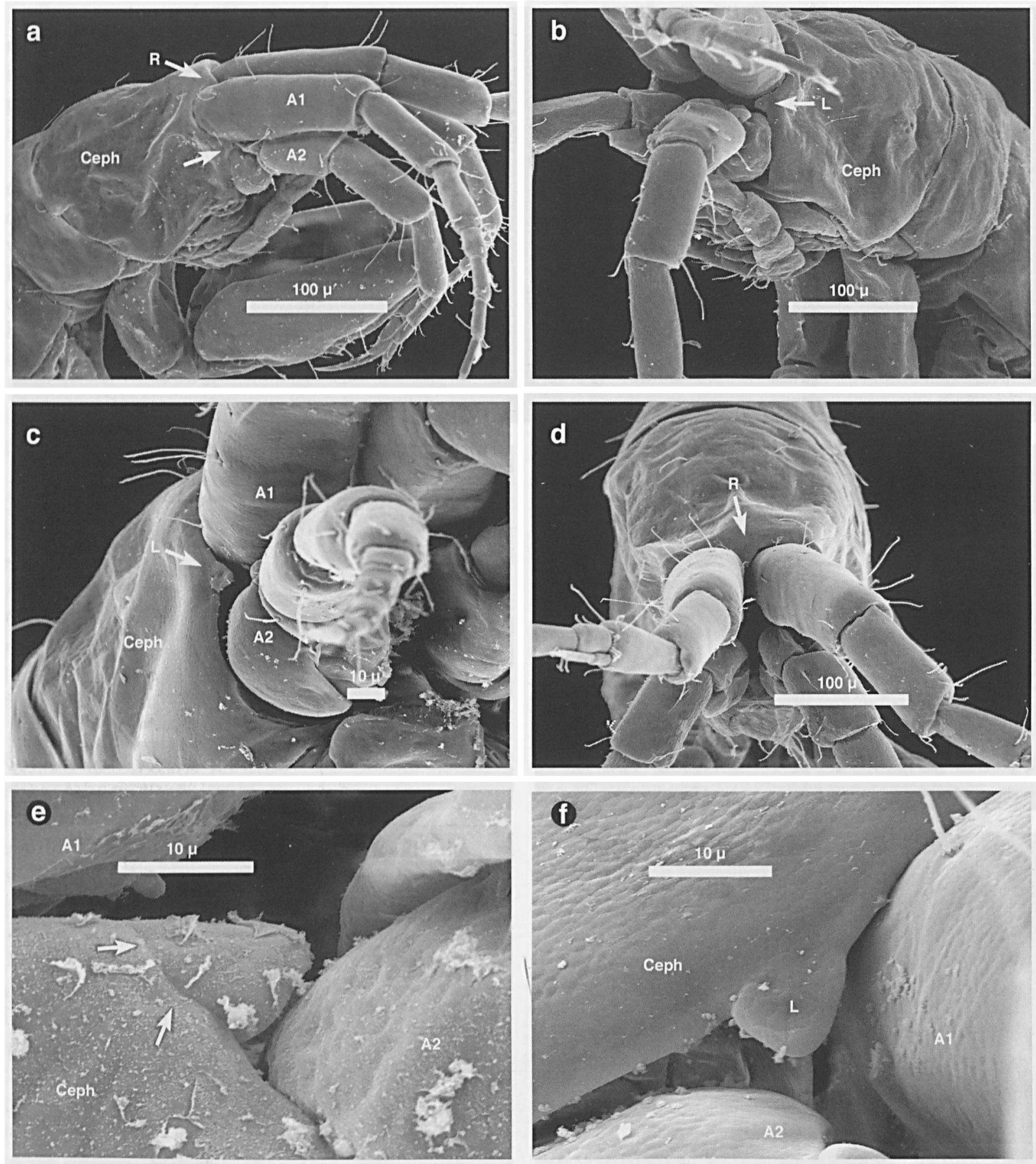

Fig. 3. Ingolfiella putealis, paratype. SEM photographs of: a - c, e,f, views from different angles on a small cephalic lobe. Photo c reflects best the possible 'closing off' function of the lobe, a similar fit is made by the tiny rostrum (d).

Fig. 4. Metaingolfiella mirabilis, paratype. SEM photographs of: a-e, views from different angles on the partially fused head region (arrows); f, cephalic lobe; $g$, ramus of third pleopod; $h$, dactylus of first gnathopod (tip form artefactually distorted). Ceph $=$ cephalic segments (cephalon and first thoracic somite with maxilliped attached). Segm $1=$ frrst body segment with first pereiopod attached. 

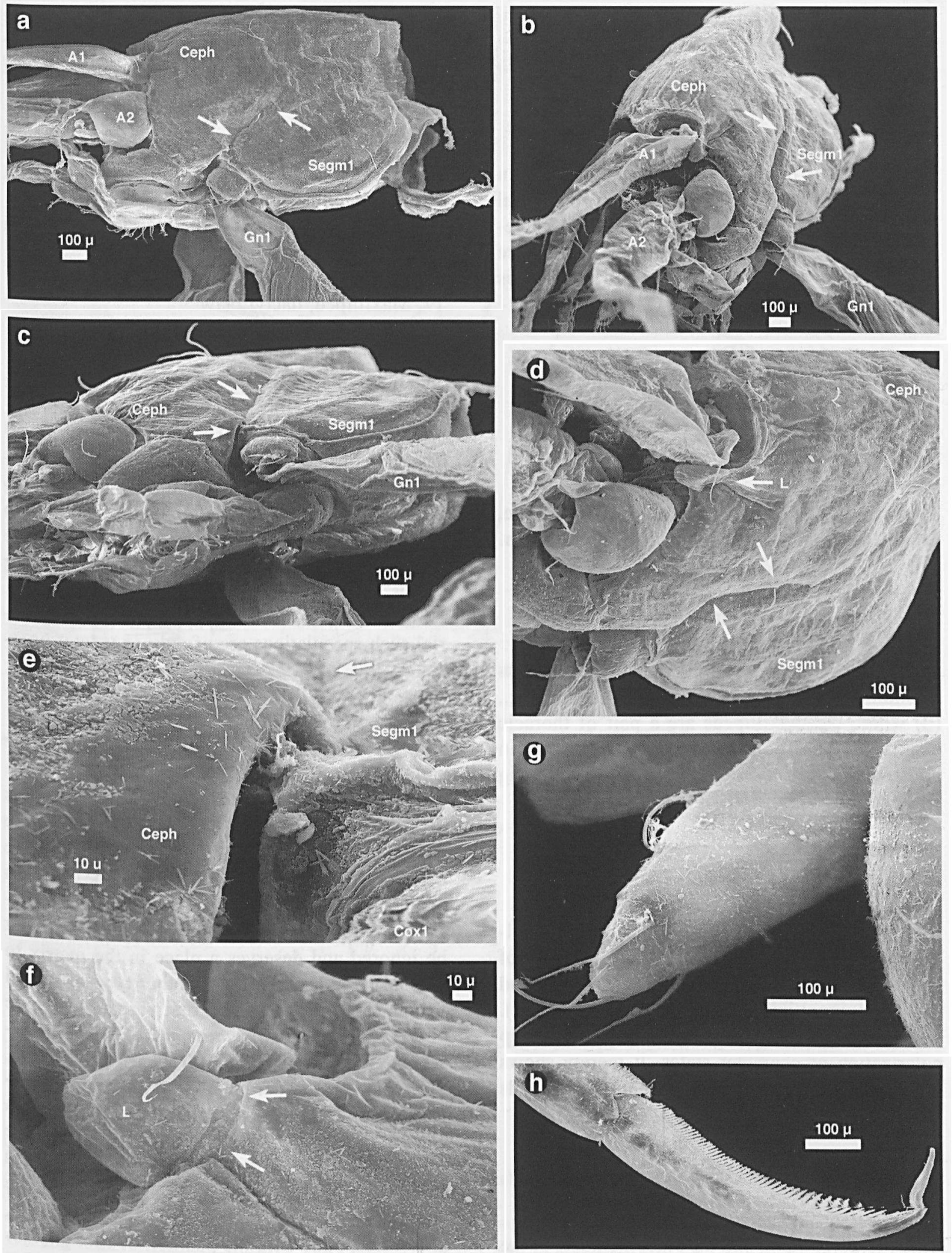
11. Maxilla 1, palp setae

state $0=$ four setae or more

state $1=$ three (Fig. 6j, m)

state $2=$ two

state $3=$ one

state $4=$ absent

The number of palp setae is a constant feature in those cases where larger numbers of individual specimens of a species where studied by us. Therefore, it is a useful diagnostic character. A decrease in the number of these setae is noted for what is seen in the out-group taxa.

12. Maxilla 2, setae number outer lobe state $\mathbf{0}=$ large complex limb with many setae state 1 = five setae, or more

state 2 = four setae (Fig. 6k)

state $3=$ three setae

state $4=$ two setae

The maxilla 2 is a greatly reduced limb with little, aside from setal number, to distinguish variation.

\section{Maxilliped basis}

state $0=$ free and separate

state 1 = fused base proximally

Free and separate bases of the maxilliped suggests a condition close to the plesiomorph situation, e.g., (0) where the maxillipeds are a pair of thoracic walking limbs. The basis is free and separate in mictaceans and in Metaingolfiella (Ruffo, 1968, fig II, 3)

\section{Maxilliped lobes}

state $0=$ with basal lobe only

state 1 = with basal and ischial lobes

Ischial lobes on the maxilliped are lacking in Ingolfiellidea and in Mictacea ( 0 ). Other members of the out-groups we employed, the bogidiellids and the pseudoingolfiellids, do have ischial lobes (1). So this character adds no information to in-group polarization of character states. It merely shows the convergent development of pseudoingolfiellids as compared to Ingolfiellidea,

15. Maxilliped, medial palp setation

state $0=$ numerous

state $1=1$ or 2 per segment

Only Metaingolfiella and the other members of the out-group share the primitive state wherein the setation displays the 'numerous' condition (0). The Ingolfiellidae all share the derived condition of a reduction to 1 or 2 setae per palp segment (1).

16. Maxilliped, lateral propodal setae

state $0=$ present

state $1=$ absent

The presence of this row of setae is recorded in only a few instances.

17. Maxilliped, dactyl claw

state $0=$ absent

state 1 = single setae

state $2=$ robust spine

state $3=$ spine with flanking setae

state 4 = falcate (Fig. 5e)

There is considerable variety in the form and number of setae on the apex of the maxilliped palp. No apparent difference in function can be ascribed to forms with one or more spines at the apex. One might be tempted to speculate that blunt and strong spines may assist in heavy food particle holding. However, without functional studies of live material such speculations are of only anecdotal interest.

18. Second thoracic segment (= first pereionite) state $0=$ free state 1 = fused to cephalon

The situation in the family Metaingolfiellidae is different from that seen in all other species in the Ingolfiellidea and in the chosen members of the out-groups. Although the half-fusion of the cephalon is an autapomorphy and thus phylogenetically uninformative in this analysis, this character cannot be ignored and deserves a place in the matrix to emphasise its peculiarity. Another type of partial fusion of the cephalon and first pereionite can be observed in Caprogammarus gurjanovae Kudrjaschov \& Vassilenko, 1966 (in Takeuchi \& Ishimaru, 1991). This particular member of the suborder Caprellidea also exhibits a partial fusion of the cephalon and first pereionite but on the ventral side of the segment, while in Metaingolfiella the fusion starts from the dorsal side (Figs. 4a-e). However, the position of the suture is similar in the two genera, and corresponds with the position of first gnatho- 


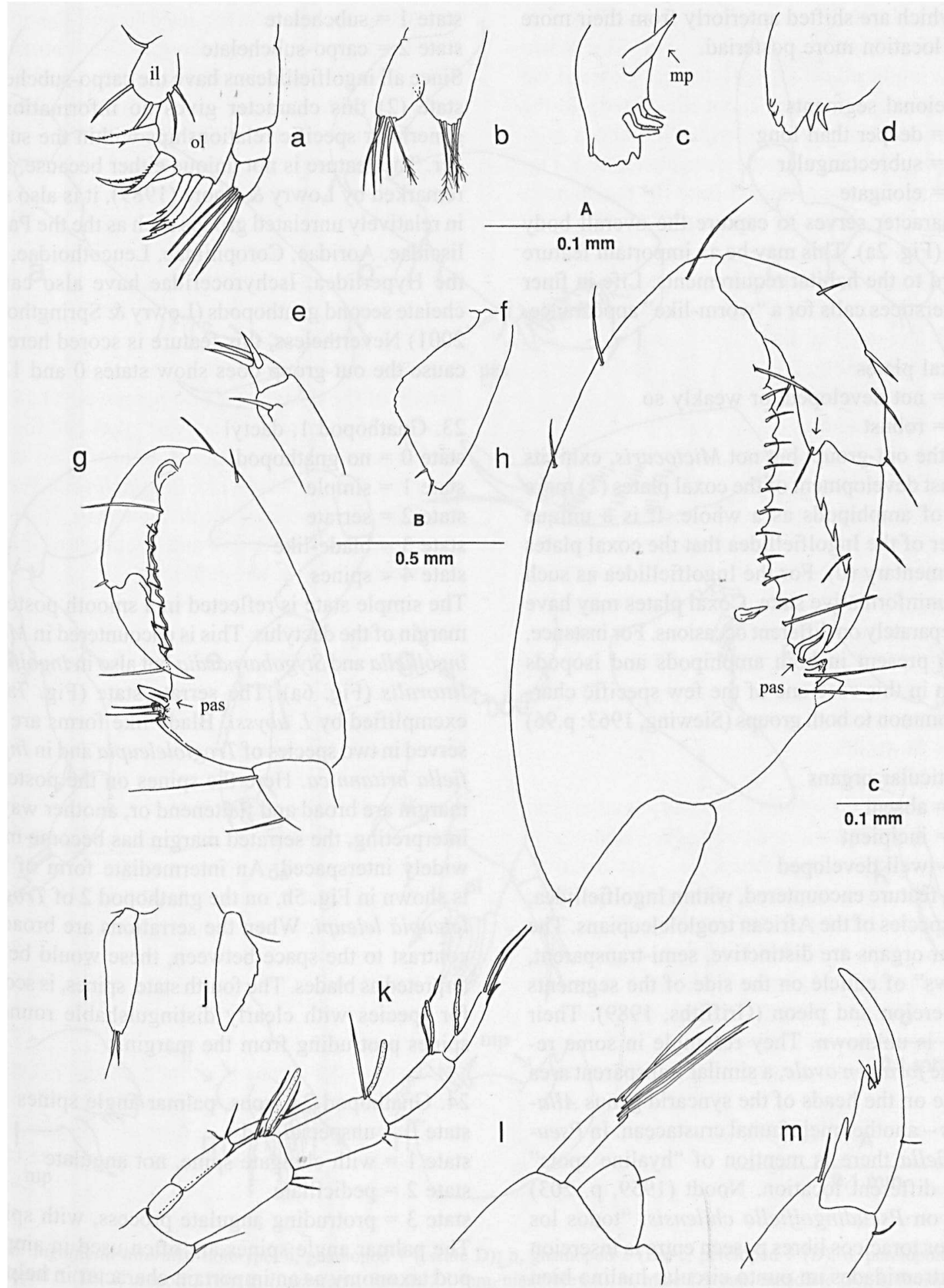

Fig. S. Trogloleleupia eggerti, male $2.6 \mathrm{~mm}$ : a, maxilla 1, left side (scale B); b, maxilla 2 (B); c, left mandible (A); d, right mandible (A); e, apex of maxilliped (B); f, female $2.3 \mathrm{~mm}$, pleopod 1 (B). g, T. leleupi male, $8.5 \mathrm{~mm}$ : gnathopod 2 (B); h, male $12 \mathrm{~mm}$, gnathopod 2 (B); i, pleopod 1 (B); j, female $7 \mathrm{~mm}$, pleopod $1(\mathrm{~B}) ; \mathrm{k}$, male $12 \mathrm{~mm}$, antenna 1 with accessory flagellum and aesthetascs (B); 1, specimen of unknown sex, from a broken pleon, urosome with exceptionally long uropod 3; m, female, $7 \mathrm{~mm}$, aberrant gnathopod 2 dactylus with 2 teeth instead of $3(\mathrm{C}) ; \mathrm{mp}=$ molar peg; il = inner lobe; ol = outer lobe, pas = palmar angle seta. 
pods, which are shifted anteriorly from their more typical location more posteriad.

\section{Pereional segments}

state $0=$ deeper than long

state 1 = subrectangular

state 2 = elongate

This character serves to capture the overall body habitus (Fig. 2a). This may be an important feature in regard to the habitat requirements. Life in finer sand interstices calls for a "worm-like" appearance.

\section{Coxal plates}

state $0=$ not developed, or weakly so

state $1=$ robust

Part of the out-group, but not Mictocaris, exhibits the robust development of the coxal plates (1) more typical of amphipods as a whole. It is a unique character of the Ingolfiellidea that the coxal plates are rudimentary $(0)$. For the Ingolfiellidea as such it is an uninformative state. Coxal plates may have arisen separately on different occasions. For instance, they are present in both amphipods and isopods but form in this case one of the few specific char-. acters common to both groups (Siewing, 1963: p.96)

\section{Lenticular organs}

state $0=$ absent

state $1=$ incipient

state 2 = well developed

This is a feature encountered, within Ingolfiellidea, only in species of the African trogloleleupians. The lenticular organs are distinctive, semi-transparent, "windows" of cuticle on the side of the segments of the pereion and pleon (Griffiths, 1989). Their function is unknown. They resemble in some respects the foramen ovale, a similar transparent area of cuticle on the heads of the syncarid genus Allanaspides - another meiofaunal crustacean. In Pseudoingolfiella there is mention of "hyaline spots" but in a different location. Noodt $(1959$, p. 203) remarks on Pseudingolfiella chilensis: "todos los segmentos toracicos libres poseen entre la insercion de las extremidades un punto circular hialino bien delimitado de funciòn desconocida".

22. Gnathopods

state $0=$ simpe limb state $1=$ subchelate

state 2 = carpo-subchelate

Since all ingolfiellideans have the carpo-subchelate state (2) this character gives no information of generic or specific relationships within the suborder. The feature is not unique either because, as is remarked by Lowry \& Poore (1989), it is also seen in relatively unrelated groups such as the the Pardaliscidae, Aoridae, Corophiidae, Leucothoidae, and the Hyperiidea. Ischyroceridae have also carpochelate second gnathopods (Lowry \& Springthorpe, 2001) Nevertheless, this feature is scored here because the out-group does show states 0 and 1 .

23. Gnathopod 1, dactyl

state $0=$ no gnathopod

state $1=$ simple

state $2=$ serrate

state 3 = blade-like

state $4=$ spines

The simple state is reflected in a smooth posterior margin of the dactylus. This is encountered in Metaingolfiella and Stygobarnardia but also in Ingolfiella littoralis (Fig. 6a). The serrate state (Fig. 7a) is exemplified by $I$. abyssi. Blade-like forms are observed in two species of Trogloleleupia and in Ingolfiella britannica. Here the spines on the posterior margin are broad and flattenend or, another way of interpreting, the serrated margin has become more widely interspaced. An intermediate form of this is shown in Fig. 5h, on the gnathopod 2 of Trogloleleupia leleupi. When the serrations are broad in contrast to the space between, these would be interpreted as blades. The fourth state, spines, is scored for species with clearly distinguishable rounded spines protruding from the margin.

24. Gnathopod 2 carpus, palmar angle spines state $0=$ unspecialized

state 1 = with elongate spine, not angulate state 2 = pedicillate

state $\mathbf{3}=$ protruding angulate process, with spine The palmar angle spines are often used in amphipod taxonomy as an important character in helping determining differences between species within one genus. These spines are often quite robust and placed at the end of where the tip of the dactylus reaches the inner margin of the propodus/carpus. In some 


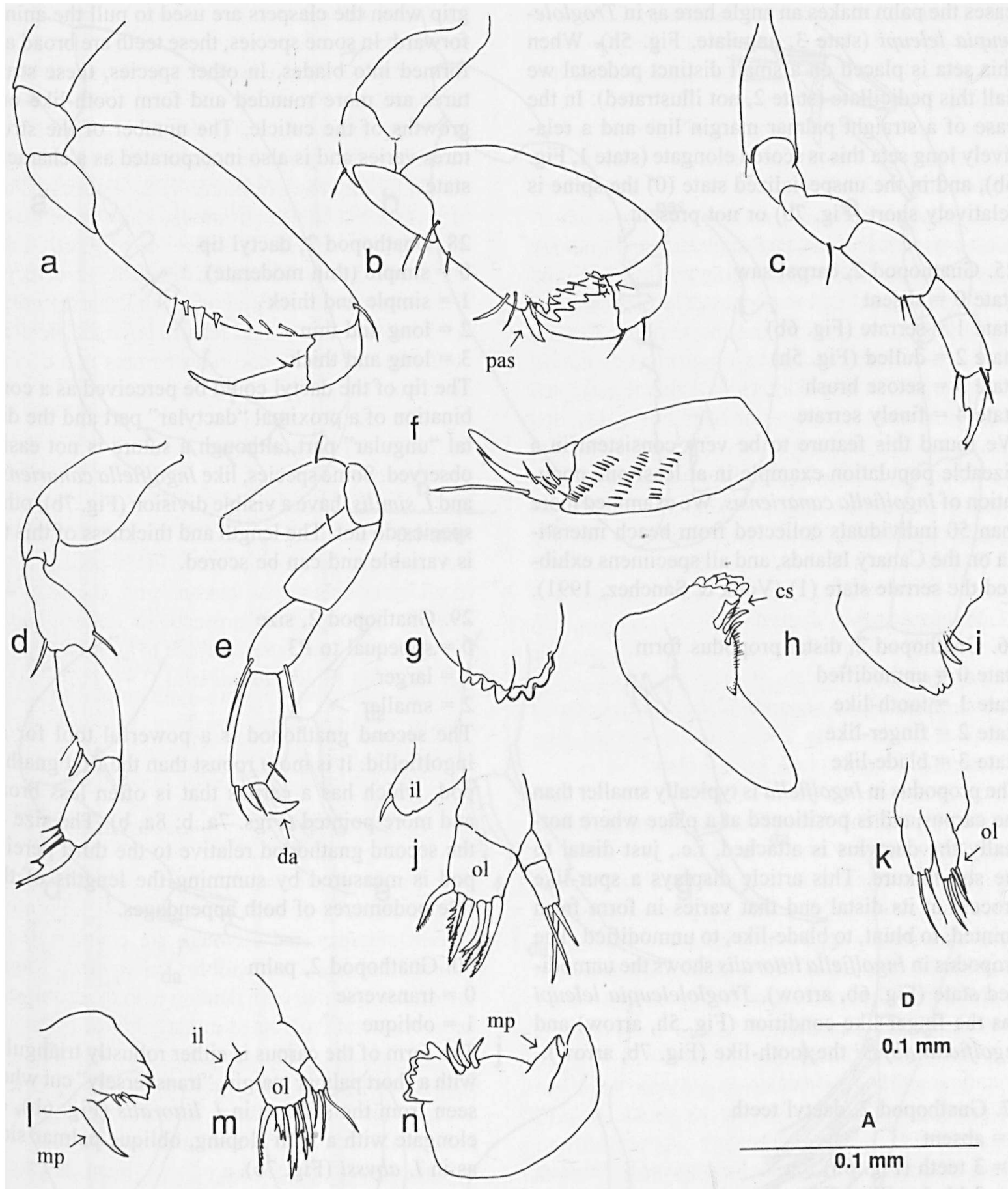

Fig. 6. Ingolfiella littoralis, holotype: a, gnathopod 1 ( scale D); b, gnathopod 2 (D); c, pereiopod 3 (D); d, pereiopod 4 (D); e, pereiopod 5 (D); f, uropod 2 (D); g, I. tabularis, female $2.1 \mathrm{~mm}$, mandible (A); h, male $1.9 \mathrm{~mm}$, mandible (A); i, female $2.1 \mathrm{~mm}$, mandible (A); j, maxilla 1 (A); k, male $1.9 \mathrm{~mm}$, maxilla 2 (A); 1, I. quadridentata, female, paratype, mandible (A); m, maxilla 1 (A); $\mathrm{n}$, I. margaritae, male holotype, mandible $(\mathrm{A}) ; \mathrm{mp}=$ molar $\mathrm{peg} ; \mathrm{il}=$ inner lobe; $\mathrm{ol}=$ outer lobe, pas = palmar angle seta; da = dactylus; $\mathrm{cs}=$ cup shaped spine. 
cases the palm makes an angle here as in Trogloleleupia leleupi (state 3, angulate, Fig. 5h). When this seta is placed on a small distinct pedestal we call this pedicillate (state 2 , not illustrated). In the case of a straight palmar margin line and a relatively long seta this is scored elongate (state 1, Fig. $6 b$ ), and in the unspecialized state $(0)$ the spine is relatively short (Fig. 7 b) or not present.

\section{Gnathopod 2, carpal saw \\ state $0=$ absent \\ state $1=$ serrate (Fig. $6 \mathrm{~b}$ ) \\ state $\mathbf{2}=$ dulled (Fig. 5 h) \\ state $3=$ setose brush \\ state $4=$ finely serrate}

We found this feature to be very consistent in a sizeable population example in at least one population of Ingolfiella canariensis. We examined more than 50 individuals collected from beach interstitia on the Canary Islands, and all specimens exhibited the serrate state (1) (Vonk \& Sánchez, 1991).

26. Gnathopod 2, distal propodus form

state $0=$ unmodified

state $1=$ tooth-like

state 2 = finger-like

state 3 = blade-like

The propodus in Ingolfiella is typically smaller than the carpus and is positioned at a place where normally the dactylus is attached, i.e., just distal to the sub-flexure. This article displays a spur-like process at its distal end that varies in form from pointed, to blunt, to blade-like, to unmodified. The propodus in Ingolfiella littoralis shows the unmodified state (Fig. 6b, arrow), Trogloleleupia leleupi has the finger-like condition (Fig. 5h, arrow) and Ingolfiella abyssi the tooth-like (Fig. $7 \mathrm{~b}$, arrow).

27. Gnathopod 2, dactyl teeth

$0=$ absent

$1=3$ teeth (Fig. $6 \mathrm{~b}$ )

$2=3$ blades (Fig. 5h)

$3=4$ teeth

$4=4$ blades (Fig. $7 b$ )

We observed differences in the form of the teeth lining the inner margin of the dactyl of the gnathopods. These thorn-like structures probably help in securing prey and/or mates, or to strengthen the grip when the claspers are used to pull the animal forward. In some species, these teeth are broad and formed into blades. In other species, these structures are more rounded and form tooth-like outgrowths of the cuticle. The number of the structures varies and is also incorporated as a character state.

28. Gnathopod 2, dactyl tip

$0=$ simple (thin moderate)

$1=$ simple and thick

$2=$ long and thin

$3=$ long and thick

The tip of the dactyl could be perceived as a combination of a proximal "dactylar" part and the distal "ungular" part, although a suture is not easily observed. Some species, like Ingolfiella canariensis and $I$. similis, have a visible division (Fig. $7 \mathrm{~b}$ ); other species do not. The length and thickness of this tip is variable and can be scored.

29. Gnathopod 2, size

$0=$ subequal to $\mathbf{P 3}$

$1=$ larger

$2=$ smaller

The second gnathopod is a powerful tool for an ingolfiellid. It is more robust than the first gnathopod, which has a carpus that is often less broad and more pointed (Figs. 7a, b; 8a, b). The size of the second gnathopod relative to the third pereiopod is measured by summing the lengths of the five podomeres of both appendages.

30. Gnathopod 2, palm

$0=$ transverse

1 = oblique

The form of the carpus is either robustly triangular with a short palmar margin, "transversely" cut when seen from the side, as in I. littoralis (Fig. 6b), or elongate with a faint sloping, oblique palmar side as in 1 abyssi (Fig. 7b).

31. Pereiopods 3 and 4 , claw

$0=$ absent

$1=$ simple

$2=$ dentate or bifid

Spiny structures on the termini of the third and fourth pereiopod may be used for better grip. Most spe- 


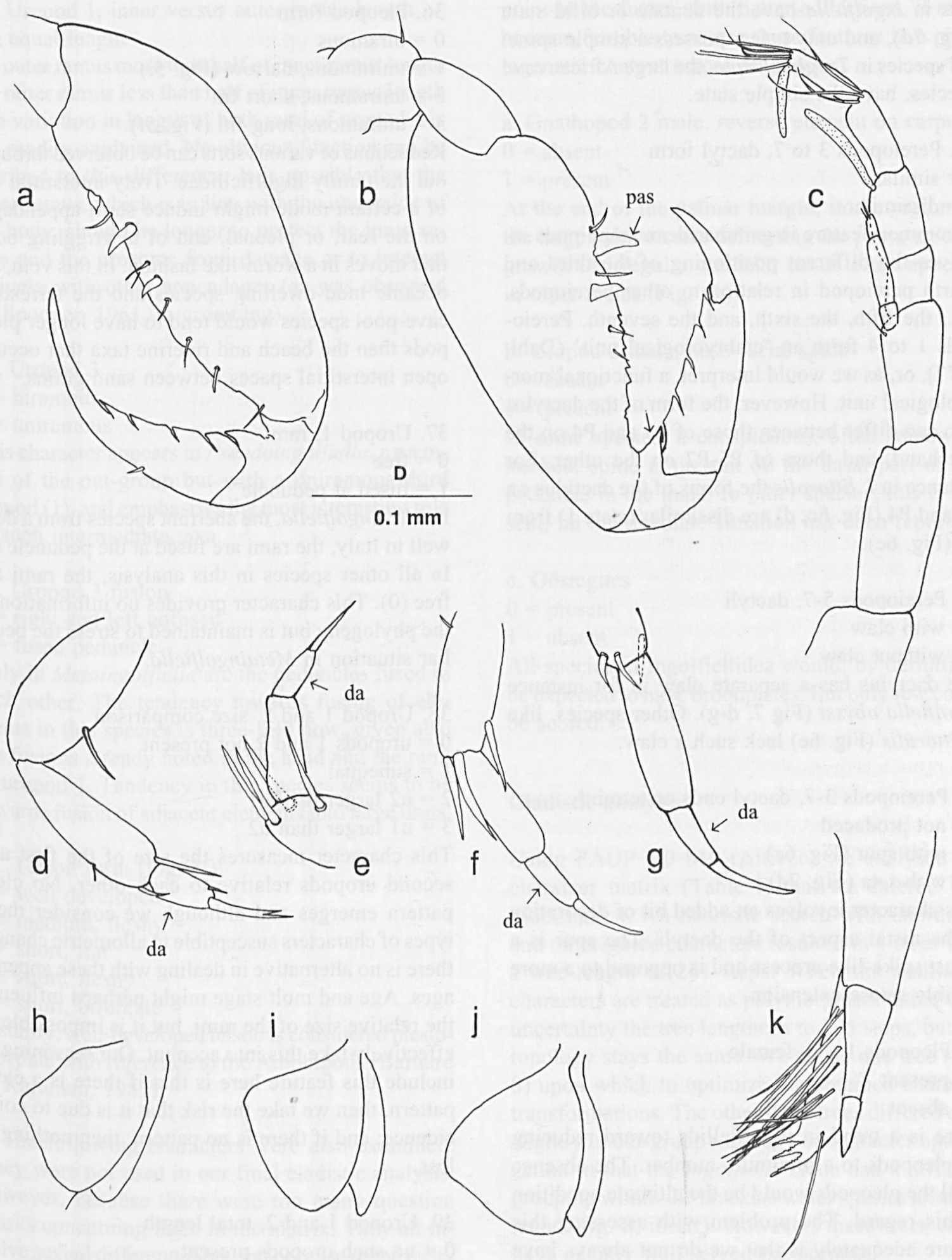

Fig. 7. Ingolfiella abyssi, holotype: a, gnathopod 1 ( scale D); b, gnathopod 2 (D); c, antenna 1 (D); d, pereiopod 3 (D); e, pereiopod 5 (D); f, pereiopod 6 (D); g, pereiopod 7 (D); h, pleopod 1 (D); i, pleopod 2 (D); j, pleopod 3 (D); $k$, uropod 1, (D); da = dactylus; pas $=$ palmar angle seta. 
cies in Ingolfiella have the dentate or bifid state (Fig. 7d), and only a few possess a simple spine. All species in Trogloleleupia, the large African cave species, have the simple state.

32. Pereiopods 3 to 7 , dactyl form

0 = similar

$1=$ dissimilar

A common feature in gammaridean amphipods involves the different positioning of the third and fourth pereiopod in relation to other pereiopods, e.g., the fifth, the sixth, and the seventh. Pereiopods 1 to 4 form an "embryological unit" (Dahl, 1977), or, as we would interpret, a functional/morphological unit. However, the form of the dactylus also can differ between those of P3 and P4 on the one hand, and those of P5-P7 on the other. For instance in I. littoralis the forms of the dactylus on P3 and P4 (Fig. 6c, d) are dissimilar (state 1) from P5 (Fig. 6e).

\section{Pereiopods 5-7, dactyli}

$0=$ with claw

$1=$ without claw

The dactylus has a separate claw in for instance Ingolfiella abyssi Fig 7. d-g). Other species, like I. littoralis (Fig. 6e) lack such a claw.

\section{Pereiopods 3-7, dactyl ends or termini}

$0=$ not produced

$1=$ with spur (Fig. 6c)

2 = with seta (Fig. 7d)

This character involves an added bit of decoration to the distal aspect of the dactyli. The spur is a robust spike-like process and is opposed to a more flexible setose extension.

35. Pleopods $1-3$, female

$0=$ present

$1=$ absent

There is a trend in ingolfiellids toward reducing the pleopods to a minimum number. The absence of all the pleopods would be the ultimate condition in this regard. The problem with assessing this feature adequately is that we do not always have sufficient samples of both sexes for some species of ingolfiellids. In males, the first pleopods always seem to be present.
36. Pleopod form

$0=$ biramous

$1=$ uniramous, narrow (Fig. 5i)

$2=$ uniramous, short fin

$3=$ uniramous, long fin (Fig. 5f)

Reductions of various sorts can be observed throughout the family Ingolfiellidae. Truly interstitial life of a certain mode might induce short appendages on the rear, or pleonal, end of a wriggling body that moves in a worm-like fashion. In this vein, the oceanic mud-dwelling species and the terrestrial cave-pool species would tend to have longer pleopods than the beach and riverine taxa that occupy open interstitial spaces between sand grains.

37. Uropod 1 , rami

$0=$ free

$1=$ fused at peduncle

In Metaingolfiella, the aberrant species from a deep well in Italy, the rami are fused at the peduncle (1) In all other species in this analysis, the rami are free (0). This character provides no information to the phylogeny but is maintained to stress the peculiar situation in Metaingolfiella.

38. Uropod 1 and 2 , size comparison

$0=$ uropods 1 and 2 not present

1 = subequal

$2=\mathrm{u} 2$ larger than $\mathrm{u} 1$

$3=\mathrm{u} 1$ larger than $\mathrm{u} 2$

This character measures the size of the first and second uropods relative to each other. No clear pattern emerges and although we consider these types of characters susceptible to allometric change, there is no alternative in dealing with these appendages. Age and molt stage might perhaps influence the relative size of the rami, but it is impossible to effectively take this into account. Our reasoning to include this feature here is that if there is a clear pattern, then we take the risk that it is due to coincidence; and if there is no pattern, then nothing is lost.

39. Uropod 1 and 2, total length

$0=$ no such uropods present

$1=$ long

$2=$ short

See comments vis-à-vis character 38 . 
40. Uropod 1, inner versus outer ramus length

$0=$ equal length

$1=$ outer ramus more than half of inner ramus length

$2=$ outer ramus less than half of inner ramus length

The variation in length of both rami of uropod 1 is not readily explained. No obvious function can be ascribed to this difference. It is possible that the outer ramus, which is in line with the underside of the body, should be longer to protect the inner ramus and the urosome from damage or to interact actively with other appendages (as was observed by Spooner, 1961, in grooming).

\section{Uropod 3 \\ $0=$ biramous \\ $1=$ uniramous}

This character appears in Pseudoingolfiella, a member of the out-group but with a uniramous third uropod (1), and emphasises the most interesting role of such intermediate taxa.

\section{Uropod 3 fusion}

$0=$ right and left unfused

$1=$ fused peduncle

Only in Metaingolfiella are the peduncles fused to each other. The tendency towards fusing of elements in this species is three-fold now, given also the fusions already noted in the head and the rami of uropod 1. Tendency in this species seems to be towards fusion of adjacent elements into large units.

$$
\begin{aligned}
& \text { 43. Telson form (Fig. 51) } \\
& 0=\text { well developed } \\
& 1=\text { medium, fleshy } \\
& 2=\text { short, flat } \\
& 3 \text { = short, fleshy } \\
& 4=\text { short, bifurcate } \\
& \text { A sturdy, well-developed telson is considered plesio- } \\
& \text { morphic with reference to the Amphipoda (Barnard } \\
& \text { \& Karaman, 1983). }
\end{aligned}
$$

The following characters were also examined. They were not used in our final cladistic analysis, however, because there were too many question marks concerning them in the matrix. They all involve sexual differentiation, and because of the rarity of most ingolfiellideans it is not always possible to have adequate sample sizes that contain both sexes. We list them here, nevertheless, because at some point in the future, with better collections, it may become feasible to assess these features in a phylogenetic context across all species.

a. Gnathopod 2 male, reverse element on carpus $0=$ absent

1 = present

At the end of the palmar margin, in the region of the large palmar setae delimiting the palm, an outgrowth of irregular cuticular tissue often appears in older males (Fig. 6h)

\section{b. Uropod 2 male, baso-facial spine \\ $0=$ absent \\ $1=$ present}

In some species, a conspicuous, often somewhat hooked, spine is present on the basal part of the peduncle in the male. In other species, this is absent, no intermediate situation has been reported.

\section{c. Oöstegites \\ $0=$ present \\ $1=$ absent}

All species in Ingolfiellidea would, by definition, be expected to have broodplates. But only few could be scored.

\section{Cladistic analysis}

Using PAUP 4.0 b10 (Altivec) we analysed the character matrix (Table I) that we entered into MacClade 4. An heuristic search with unordered and unweighted characters resulted in 4 trees with a tree length of 261 steps. When the multistate characters are treated as polymorphism rather than uncertainty the tree lengthens to 295 steps, but the topology stays the same. We chose one tree (Fig. 8) upon which to optimize the obtained character transformations. The other three trees differed only slightly in out-group topology or character optimization in that the Ingolfiella clade had a different grouping within the brackish water species arrangement (Fig. 8, insert). However, these trees could have equally well served the purpose.

The analysis used Mictacea and selected gammaridean amphipods as out-groups. The suitability of Mictocaris halope as an out-group taxon arises 
from its comparable habitat requirements - marine caves on Bermuda - and also a similarity in form and position of oöstegites that are of "gammaridean amphipod type" (Just \& Poore, 1988). In addition, the lobe on the frontal margin of the cephalon is comparable to the equally enigmatic lobes in Ingolfiellidea. Mictocaris also possesses reduced pleopods. The plesiomorphic state of cephalic and thoracal appendages serve as a basis for polarizing supposedly homologous features in the other taxa included in the analysis.

The gammaridean amphipods Bogidiella Hertzog, 1933, and Pseudingolfiella Noodt, 1965, have closer affinities to ingolfiellideans than Mictocaris. Bogidiella has reduced pleopods and a strictly stygobiont life cycle, with most representatives living in fresh water but also a few in the brackish and marine environment. Their body plan is certainly less reduced, and thus holds potentially more plesiomorphies, than that of the ingolfiellideans. The overall habitus of Pseudingolfiella earned this genus its name. Pseudingolfiella has much reduced pleopods, as in Ingolfiellidae. Two species are known: Pseudingolfiella chilensis (Noodt, 1959) and Pseudingolfiella soyeri Coineau, 1977. We used both of them in the out-group as bridging forms between Ingolfiellidea and Mictocaris, and as stand-ins for the gammaridean amphipods.

We have considered using as out-groups the other two remaining, exclusively marine, suborders in the Amphipoda: Caprellidea and Hyperiidea. However, many characters in our matrix would have been left unscored. The adaptations found in caprellids and hyperiids, which relate to their very different way of living, made them an unlikely choice for comparison. Caprellids cling to sea weeds and lower metazoans in the sublittoral zone, and they have a strongly modified pleon. Hyperiids are pelagic with a highly modified head region.

\section{Results}

The cladogram (Fig. 8) reveals a far from random array of species. The out-group, Mictocaris, Bogidiella and the two species of Pseudingolfiella, remained apart from the in-group whether or not we enforced an out-group constraint in PAUP. We have placed capital letters to focus attention on the most interesting branches of the cladogram. These branches display good apomorphies, i.e., with high consistency indexes. For instance, the lack of an ischial lobe (character 14) on the maxilliped in Mictocaris halope results in a strong emphasis by the program on the presence of this lobe in Bogidiella and Pseudingolfiella. This example is also illustrative of how such changes must be interpreted in a relative way. The mictaceans are not necessarily a close sister group to the bogidiellids and pseudingolfiellids (node A). We lack in fact countless numbers of species relevant to amphipod history that never made it through to the present, and we undoubtedly lack many deep groundwater forms that could enlighten us on the origins and early evolution of the group. We merely wish to say, before we go on to interpret character state changes, that given these taxa and these particular characters, and provided one watches out for specific assumptions, then the particular phylogenetic patterns we obtained seem to prevail.

At the base of the ingolfiellidean clade, we note Metaingolfiella, characterized by the uniquely partially fused second thoracic segment into the head, and the fusion of elements in uropod 1 rami and uropod 3 peduncles. (This last feature is interesting in regard to the caudal furca/rami situation in other crustaceans, Schram \& Koenemann, in lit.). Nevertheless, these autapomorphies are associated with many plesiomorphic features that insures this species remains at the base of the ingolfiellidean clade.

Stygobarnardia (node B) regains a vestigial mandibular palp in this scenario. It was lost in the transition from the out-group to the in-group (node A). While such character reversals appear to pose problems for diagnosing taxa, they can perhaps best be understood in terms of paedomorphic shifts of developmental timing of events.

The "trogloleleupians" emerge as paraphyletic. The members of a small clade (node C), made up of $T$, eggerti, $T$. dracospiritus and T. leleupi, share weakly developed lenticular organs, while the other two "trogloleleupian" species are set off by having either strongly developed lenticular organs, or a differently implanted palmar angle seta. Two new genera are necessary to recognize their isolated locations on the tree. 


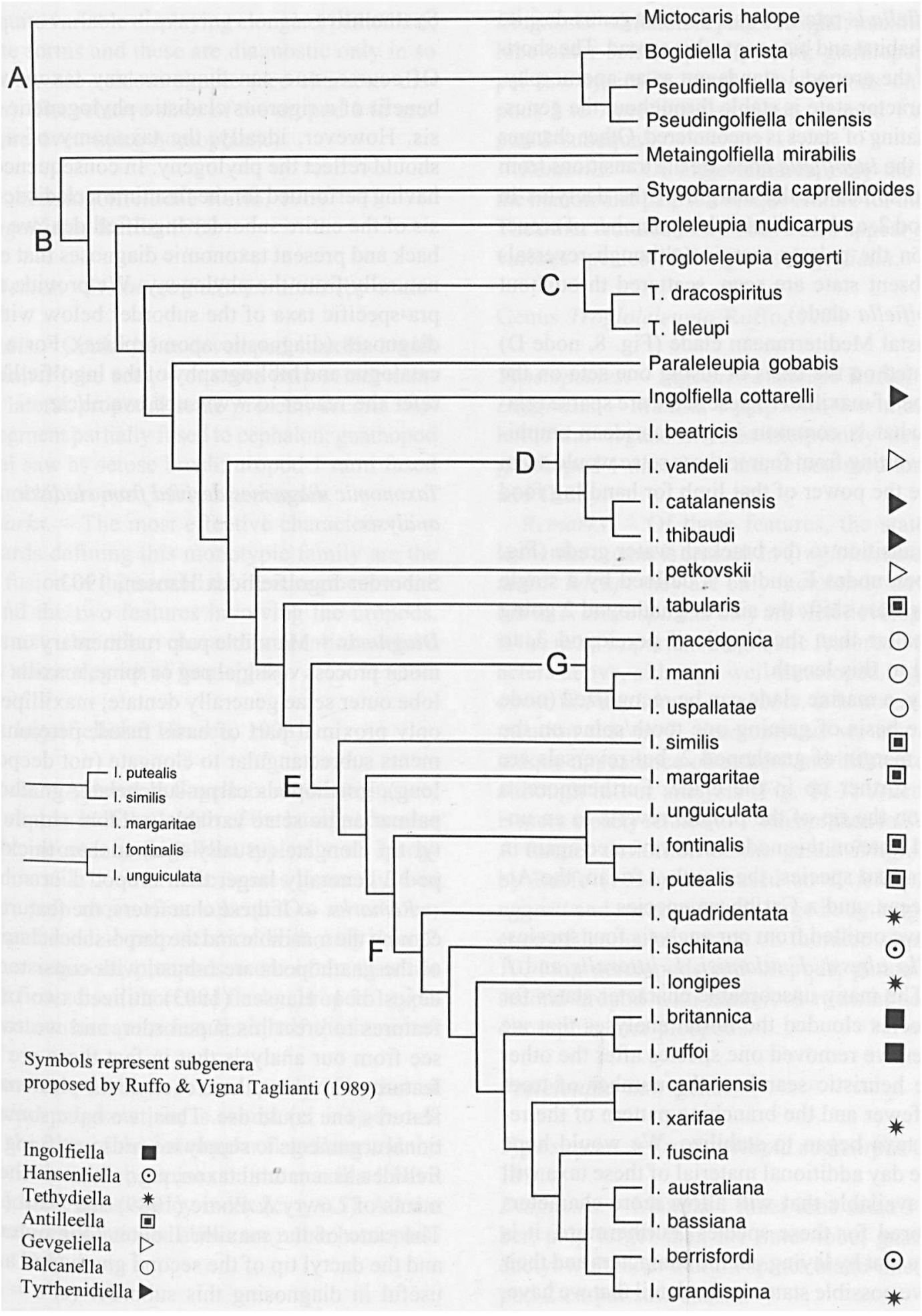

Fig. 8. Tree number 1 (rooted by using user-specified outgroup): Tree length $=261$, Consistency index, $(\mathrm{CI})=0.3511, \mathrm{Homoplasy}$ index $(\mathrm{HI})=0.6489, \mathrm{CI}$ excluding uninformative characters $=0.3436$, HI excluding uninformative characters $=0.6564$, Retention index $(R I)=0.5550$, Rescaled consistency index $(R C)=0.1949$. Capitals $(A-G)$ on several nodes represent groups ( see text). Species of Ingolfiella without a symbol for subgeneric classification entered the literature after 1989. Insert: alternative topology within the brackish water clade. 
Ingolfiella îs retained as a dístinct genus despite its wide habitat and biogeographic spread. The shortening of the uropod 1 stands out as an apomorphy. This character state is stable throughout the genus, no alternating of states is encountered. Other changes defining the Ingolfiella node are the transitions from blades to spines on the margin of the dactylus in gnathopod 2, and the diminishing number of crenelations on the palmar margin (although reversals to the absent state are seen, scattered throughout the Ingolfiella clade).

A coastal Mediterranean clade (Fig. 8, node D) is separated on the basis of losing one seta on the inner lobe of maxilla 1 . These setae are sparse relative to what is common in gammaridean amphipods. Reverting from four to three setae would seem to reduce the power of that limb for handling food particles.

The transition to the brackish water grade (Fig. 8 , between nodes $\mathrm{E}$ and $\mathrm{F}$ ) is defined by a single character state shift: the size of gnathopod 2 going from smaller than the length of pereiopod 3, to subequal to this length.

Finally, a marine clade can be recognized (node F) on the basis of gaining one tooth/spine on the dactylar margin of gnathopod 2, but reversals are possible further up in the clade. Furthermore, a process on the tip of the propod reverts to an unmodified state on this node but is reversed again in the Australian species, the South-African, the Atlantic Ocean, and a Caribbean species.

We have omitted from our analysis four species: Ingolfiella abyssi, I. atlantisi, I. littoralis and $I$. kapuri. The many unscoreable character states for these species clouded the initial analyses that we ran. When we removed one species after the other from the heuristic searches, the number of trees became fewer and the branching pattern of the remaining taxa began to stabilize. We would hope that some day additional material of these taxa will become available that will allow more characters to be scored for these species. Furthermore, it is our desire that by laying out the characters and their alternative possible states in the detail that we have, that future describers of ingolfiellidean species will become more focussed on what descriptors they should seek to elicit from the study of their specimens than has been the case up to this point.

\section{Systematics}

Of course, one can diagnose any taxon without benefit of a rigorous cladistic phylogenetic analysis. However, ideally, the taxonomy of a group should reflect the phylogeny. In consequence, now having performed for the first time a cladistic analysis of the entire suborder Ingolfiellidea, we can go back and present taxonomic diagnoses that emerge naturally from the phylogeny. We provide the supra-specific taxa of the suborder below with such diagnoses (diagnostic apomorphies). For a world catalogue and bibliography of the Ingolfiellidea we refer the reader to www.uba.uva.nl/ctz

\section{Taxonomic diagnoses derived from cladistic analysis}

Suborder Ingolfiellidea Hansen, 1903

Diagnosis. - Mandible palp rudimentary or absent, molar process vestigial peg or spine; maxilla 1 outer lobe outer setae generally dentate; maxilliped with only proximal part of basis fused; pereional segments subrectangular to elongate (not deeper than long); gnathopods carpo-subchelate; gnathopod 2 palmar angle setae variable (seldom simple), dactyl tip elongate (usually thinner than thick); uropod 2 generally larger than uropod 1 or subequal.

Remarks. - Of these characters, the features concerning the mandible and the carpo-subchelate nature of the gnathopods are robust, with consistency indexes of 1. Hansen (1903) utilized two of these features to erect his superorder, and we can now see from our analysis that in fact these are robust features. However, these exclude the plesiomorphic features one could use. Thus, we have some additional arguments to supply towards justifying Ingolfiellidea as a natural taxon, e.g., vis-a-vis the arguments of Lowry \& Poore (1989) and Dahl (1977). The state of the maxilla 1 outer lobe outer setae and the dactyl tip of the second gnathopod are also useful in diagnosing this suborder (ci's $=0.4$ or higher). However, the other features, while helping to define the clade on in our analysis, nevertheless, are rather homoplastic characters. For instance, the palmar angle setae of the second gnatho- 
pod is quite variable displaying elongate, pedicillate, angulate forms and these are diagnostic only in so far as they are seldom simple (see character discussion). The relative sizes of the uropod 1 to uropod 2 are even more homoplastic.

Family Metaingolfiellidae Ruffo, 1969

Metaingolfiella Ruffo, 1969

Type species. - Metaingolfiella mirabilis (by monotypy)

Diagnosis. - Ocular lobes developed; maxilla 1 with single inner lobe seta, 4 or more palp setae; maxilliped lateral propodal setae present; second thoracic segment partially fused to cephalon; gnathopod 2 carpal saw as setose brush; uropod 1 rami fused to peduncle; uropod 3 fused peduncles.

Remarks. - The most effective characters (ci = 1) towards defining this monotypic family are the partial fusion of the second thoracic segment to the head and the two features involving the uropods. In contrast, the other characters mentioned here display some degree of homoplasy.

Family Ingolfiellidae Hansen, 1903

Diagnosis. - Antennule flagellum moderate in size, i.e., more than half the length of the basal peducular segment, accessory flagellum typically of 3 segments; maxilla 1 outer lobe spines generally 6 in number, palp most often subequal to outer lobe; maxilliped medial palp setation with only 1 or 2 setae per segment; pleopods more often than not as short fins; telson short and fleshy; uropod 1 typically with outer ramus less than half the inner ramus.

Remarks. - Of these features, only one, that of the medial palp setation, is robust (ci = 1). In addition, the size of the antennular flagellum and the number of outer lobe spines on the maxilla 1 have an acceptable consistency index (ci $\geq 0.5$ ). All the other features mentioned above are rather homoplastìc $(\mathrm{ci}<0.5)$.

\section{Genus Stygobarnardia Ruffo, 1985}

Type species. - Stygobarnardia caprellinoides Ruffo, 1985 (by monotypy)
Diagnosis. -Mandíble palp vestigial; maxilla 1 outer lobe outer setae typically bifid; gnathopod 2 carpal saw typically serrate; dactyl ends on pereiopods 3 to 7 produced as a seta; uropod 1 and uropod 2 subequal.

Remarks. - Of these features, only the state of the mandibular palp is a unique feature for this genus. The other features noted above also appear amongst various species of the genus Ingolfiella.

\section{Genus Trogloleleupia Ruffo, 1974}

Type species. - Ingolfiella leleupi Ruffo, 1951. Diagnosis. - Maxilla 1 palp with 4 or more setae; lenticular organs at least incipiently developed; gnathopod 1 dactyl serrate; telson medium in size and fleshy.

Remarks. - Of these features, the state of the lenticular organs is critical. In Trogloleleupia eggerti and $T$. leleupi they are only incipiently developed, but in $T$. dracospiritus they are well developed. This is the most important diagnostic feature of the characters above, although well-developed organs also occur in Paraleleupia gobabis. It is noteworthy to mention that in $T$. dracospiritus we also see the unique appearance of a short and bifurcate telson, although in our analysis (Fig. 8) $T$. dracospiritus is more closely related to $T$. leleupi than to $T$. eggerti. A former definition of the genus Trogloleleupia by Ruffo (1964) was based on T. leleupi and $T$. eggerti and mentions their large body length, presence of lenticular organs on thoracic segments 310 , long pereiopods and uropods, peducle of the second uropod with numerous rows of setae, and dimorphic first pleopods.

\section{Proleleupia new genus}

Type species. - Trogloleleupia nudicarpus Griffiths, 1991.

Diagnosis. - Maxilla 1 inner lobe setae 3 in number, palp larger than the outer lobe; gnathopod 1 dactyl with inner margin spines blade-like; gnathopod 2 carpal saw absent.

Remarks. - A separate genus, Proleleupia, for what was known as Trogloleleupia nudicarpus Griffiths, 1991 is required by our cladistic analysis, wherein the formerly large-bodied genus Troglole- 
leupia Ruffo, 1974 emerged as a paraphyletic taxon. I ne core species of the trogloleleupian group, containing the type species for Trogloleleupia, T. leleupi (Ruffo, 1951), is part of a fairly distinct clade, but two of the five species formerly placed in the genus Trogloleleupia in fact sort separately from this core species group. In addition, Proleleupia nudicarpus is the only trogloleleupian that lacks lenticular organs, a negative feature to be sure, but nonetheless one that separates it from all the other large-bodied trogloleleupians.

\section{Paraleleupia new genus}

\section{Type species. - Trogloleleupia gobabis Griffiths, 1989}

Diagnosis. - Pereional segments sub-rectangular; lenticular organs well developed; gnathopod 2 dactyl teeth developed as 4 blades, dactyl tip simple; pleopods as long fins; uropod 1 and uropod 2 subequal.

Remarks. - A separate genus, Paraleleupia, for what was known as Trogloleleupia gobabis Griffiths, 1989 is required by our cladistic analysis, wherein, as mentioned earlier the large-bodied genus Trogloleleupia Ruffo, 1963 emerged as a paraphyletic taxon. Its well-developed lenticular organs clearly characterize Paraleleupia gobabis, a feature shared only by $T$. dracospritus. In addition, the simple dactyl tip on the second gnathopod is a feature seen also in $T$. eggerti but no place else amongst all the ingolfiellideans. By erecting separate genera for Proleleupia nudicarpus and Paraleleupia gobabis we effectively set up an hypothesis of taxonomic relationships in this part of the tree. We can test this hypothesis either with discovery of future "trogloleleupians', or accumulation of sequence data, or further insight into gross features of morphology.

\section{Ingolfièlla Hansen, 1903.}

Type species. - Ingolfiella abyssi Hansen, 1903. Diagnosis. - Gnathopod 1 dactyl either as a simple spine or serrate, gnathopod 2 palmar angle seta not pedicillate, carpal saw typically serrate; dactyl ends on pereiopods 3 through 7 typically produced as a spur; uropods 1 and 2 short.

Remarks. - The nature of the short uropods and the lack of a pedicillate palmar angle seta on gnatho- pod 2 stand out as very diagnostic for the species within the ingolfiellideans. These characters are quite stable throughout the genus: no alternate states concerning the uropods are encountered, and diverse variants of the palmar angle seta can be seen except the pedicillate form. In addition, species of Ingolfiella generally have a serrate carpal saw on gnathopod 2, exceptions being $I$. cottarellii, in which it is uniquely finely serrate, and $I_{x}$ beatricis, $I_{x}$ macedonica, I. xarifae, I. fuscina, and I. grandispina, in which it is absent.

The genus Ingolfiella is retained here as a single, undivided taxon, even though it is world wide in distribution and can be found in localities ranging from fresh groundwater, through diverse brackish, to deep-water ocean habitats. Given this wide distribution and variety of habitats it is instructive to examine several points on the cladogram for Ingolfiella with further comment as to character state changes.

A coastal Mediterranean clade (Fig. 8, Node D) is separated on the basis of loss of one seta on the outer lobe of the maxilla 2. These setae are reduced relative to what is common in gammaridean amphipods. Reverting from 4 setae to 3 setae would seem to reduce the ability of this limb to handle food particles. This may appear as a "subtle" feature, nevertheless the members of this clade exhibit a relatively high degree of geographic proximity.

The change over point from freshwater to brackish habitats (Fig. 8, Node E) is also defined by a single character state transition: the size of gnathopod 2 shifts from being smaller than the length of pereiopod 3 to being subequal to the latter. It again is difficult to conceive of any purported selective advantage of such a feature. Nevertheless, this node marks a distinct habitat shift within the genus. Another critical habitat shift occurs into pure marine waters (Fig. 8, Node F) and corresponds with changes in aspects of the second gnathopod. At this point we note an alteration of ornament on the dactylar margin of gnathopod 2, going from 3 blade-like processes to 3-4 teeth. Furthermore, we also note increasing variability on the distal propodus of gnathopod 2. Most freshwater Ingolfiella display blade-like distal propodi. Within brackish habitats we also see a finger-like form appearing. In 
the marine realm, an unmodified propodus reappears, a structural form characteristic of taxa typically outside the genus.

What surprises us about the above points is that while the habitat or geographic shifts are rather striking, the anatomical changes at these points are subtle in the extreme.

Past authors (S. Karaman 1959, Stock 1976b, Ruffo 1970, and Ruffo \& Vigna Taglianti 1989), have made arguments to subdivide the genus Ingolfiella into either more genera, or at least subgenera (see bibliography). As can be seen in Fig. 8, these subgenera have little value in light of the cladistic analysis here. Nevertheless, we do see clades appearing within the genus. We have already noted the Mediterranean clade of the $I$. beatricis species group, characterized by a single feature. Another such clade is the $I$. macedonica species group (Fig. 8 , Node G). This clade is characterized by two good features: 1 ) the claws of pereiopods 3 to 4 are simple in form, and 2) pereiopods 3 to 7 dactyls lack any decoration such as spurs or setae. These are good features at that point in the tree. If characters nicely delineating discrete clades would justify the erection of subgenera in a cladistic context, one might be tempted to look upon the so-called $I$. macedonica species group as a good one. We might even be tempted to say this species group is even more robust than that of $I$. beatricis species group discussed above, which only has a single, rather subtle diagnostic feature. However, the I. beatricis group is geographically continuous, while the members of the so-called I. macedonica species group are hardly so: $I$, macedonica is found in northwestern Greece, I. manni was collected from northern Chile and $I$. uspallatae comes from the high Andean passes of western Argentina. How do we bridge the gap from the Balkans to South America?

Thus, at this time we see no justification for establishing subgenera, or breaking up Ingolfiella into separate genera. The shifting morphological changes noted amongst the optimized characters on the cladogram are too subtle and homoplastic, and discrete clades are too few and far between. We remain confident, however, that as more taxa are added to the genus the cladogram will acquire some additional structure. Then at that time, the issue of what to do with such a wide ranging, both geographically and ecologically, genus as Ingolfiella currently represents can be revisited.

\section{Additional descriptions}

Re-examination of type and other material in light of the cladistic analysis allows additions and revisions to be made to existing species descriptions.

\section{Metaingolfiella mirabilis Ruffo, 1969}

Fig. 4a-h

Material examined. - collection of the Natural History Museum Verona.

Additional redescription: cephalon fused over about half the lateral lower side with the first pereionite.

Trogloleleupia eggerti (Ruffo, 1964)

Fig. 5a-d

Material examined. - collection of the Natural History Museum Verona.

The allotype (female) designated by Ruffo was restudied and some more sexual dimorphism is reported. Not only is the form of the first pleopod different - elongate in males and triangular in females - as mentioned by Ruffo, but also the female lacks a hooked spine on the base of the peduncle of the first uropod and the claviform process on the peduncle of the second uropod. Another noteworthy difference is the lack of the palmar corner process in the second gnathopod, but this occurs in other ingolfiellids too.

Additional description:

Maxilla 1, (Fig 6 a) palp two-segmented with 4 setae on distal segment. Outer lobe with 6 serrated and combed robust setae. Inner lobe with 5 setae almost evenly distributed along its margin.

Maxilla 2 (Fig 6b), with both lobes having 5 setae, some plumed.

Mandible (Fig 6c, d). Left side with pointed pars molaris and 3 hooked and serrate spines at the base of the masticatory teeth. Right side with two such curved hooks.

Maxilliped (Fig. 5e). Palp with 3 spines apically "and 1 spinule on a small pedestal submarginally on the propodal segment.

Pleopod 1 (Fig. 5f). Triangular fin with a slightly 
serrated hind corner margin and 3 tiny spinules on the lower margin

\section{Trogloleleupia leleupi Ruffo, 1951}

Material examined. - British Museum, Lusaka Boreholes, Zimbabwe, 9 specimen; Zoological Institute and Museum, University of Hamburg, 15 specimens, Kivu, Distric de Kindu, Territoire de Kasongo, Grotte de Mwana-Kussu, Congo, 24-X-1954

In the descriptions of Ruffo (1951) and Ingle (1961) no special emphasis was placed on the form of the first pleopod. These pleopods have in most ingolfiellids a different form in males and females. However, in the many specimens of Trogloleleupia (44 + from Belgian Congo and 9 from Lusaka, Zimbabwe), no distinction could be made between the sexes. We checked the pleopods for such differences. Indeed, some of the smaller specimens carry the digitiform first pleopods with two setules on the apex typical of males, while the larger specimens have the more spatulate crenelated type as in pleopod 2 and 3. Additional description:

Antenna 1 (Fig. 5k) with a 4-segmented flagellum, bearing an aesthetasc on each segment. Accessory flagellum 3-segmented.

Gnathopod 2 (Fig. $5 \mathrm{~g}$, h) differs in aspect with increasing size. the $8 \mathrm{~mm}$ male (6e) has a hyaline lobe aligning the margin right under the palmar process but this is not seen in a $12 \mathrm{~mm}$ specimen (Fig. 5h), with a sculptured palmar process. The crenelations are more numerous on the palmar margin.

Pleopod 1 (Fig. 5i, j) is long and slender in the male, having two setae on the apex. the female form is somewhat triangular and lightly serrate on the hind margin.

Uropod 3 (Fig. 5l) in one instance quite long, with five slender setae on its apex.

\section{Ingolfiella littoralis Hansen 1903}

Material examined - Holotype specimen, Zoological Museum of Copenhagen (ZMUC-CRU-7088) Additional description:

Gnathopod 1 (Fig. 6a), margin of palm smooth, without structures or serrations
Gnathopod 2 (Fig. 6b), margin of palm serrated. Pereiopod 3, 4 (Fig. 6c, d), claws tapering to a forked end

Pereiopod 5 (Fig. 6e), claw thick, undifferentiated. Uropod 2 (Fig. 3g), with three oblique rows of setules on the inner side of the peduncle and a small group of setules on the inner side of the inner ramus.

\section{Ingolfiella tabularis Stock 1977}

Material examined. - Zoological Museum of Amsterdam, paratypes, cat. nr. 106.107

Additional description:

Mandible (Fig. 6g, h, i), with cup shaped spine on left mandible.

Maxilla 1 (Fig. 6j), with 6 combed and serrate setae of irregular length on outer lobe. Inner lobe with 1 seta, palp with 3 setae on apex.

Maxilla 2 (Fig. 6k), fitted with sparse setae on both lobes.

\section{Ingolfiella margaritae Stock 1979}

Material examined. - Zoological Museum of Amsterdam, holotype cat. nr. $106.443-444$

Additional description:

Mandible (Fig. 6n), with apparently broken off molar process. Left or right side could not be discerned. Three curved spines just below pars incisiva.

\section{Ingolfiella quadridentata Stock 1979}

Material examined. - Zoological Museum of Amsterdam, paratypes cat. nr. $106.445-446$

Additional description:

Mandible (Fig. 61) with pointed molar process. Three very small spinules below the pars incisiva Maxilla 1(Fig. $6 \mathrm{~m}$ ) has an outer lobe with 6 robust spines, bifid or serrate. Inner lobe with 1 seta, palp with 3 on apex.

Ingolfiella abyssi Hansen 1903

Material examined. - Museum of Copenhagen ZMUC-CRU-5030

Additional description:

Antenna 1 (Fig. 7c), with 4-segmented flagellum, 
bearing aesthetascs on the second and fourth segment. Accessory flagellum 3-segmented.

Gnathopod 1 and 2 (Fig. 7a, b), with 4 incisions on the inner margin of the dactylus, forming 4 blades. Gnathopod 2 claw with a clear articulation between dactylus and unguis.

Pereiopods 3-7 (Fig. 7d-g), with bifid claws in p3 and p4 (8d) and straight in p5-7 (8e, f, g)

Pleopods 1-3 (Fig. 7h-j), with more or less triangular form.

Uropod 1 (Fig. 7k), with 3 spiniform processes (instead of 4 in the original description) on inner ramus. Outer ramus with a breach on two-thirds of its length, dividing the ramus in two articles.

\section{Biogeographic analysis}

An accepted approach to elucidating patterns of historic biogeography would typically begin with either a Brooks Parsimony, or COMPONENT Analysis. This would require that the distribution information (Fig. 9) be converted into a supplementary matrix, which would then be subjected to further analysis. Though effective and widely accepted, these methods pose some conceptual disadvantages. The biogeographic analysis is performed on top of the results of a previous cladistic analysis. This imposes a number of new equally parsimonious trees on top of the supposedly equally parsimonious trees from the base analysis. In effect, one accumulates uncertainty on top of uncertainty.

There are, of course, ways to handle all these alternative trees, but there is an additional conceptual problem to this approach. This treats the biogeographic history as if it were a completely separate and subsequent set of events in the evolution of a group when in fact the spatial and distributional components are an integrated part of a taxon"s biology. One possible solution to this could be to attach a step matrix to the primary analysis that would code for all possible biogeographic movements within the recorded range of the group in question (Berge, 2000). The biogeography could then be integrated into the base analysis. This is worthy of further exploration within the Amphipoda, but must be the subject of a separate study.

A conceptually simpler approach, however, is suggested by the data at hand. The biogeographic history of the separate clades (Fig. 8, nodes A-G) can be projected onto paleomaps (see Ebach \& Humphries, 2002). This is a process of straightforward inspection. But where to begin? Since our cladogram clearly points to an early development of the large fresh water African and Mediterranean cave species it leads us to look for a paleomap, in this case Triassic, that would combine both areas and show a continuous land mass with those areas present at some particular point in earth history. Actual fossil evidence for the existence of the Amphipoda does not go beyond approximately $40 \mathrm{mil}-$ lion years ago (Coleman and Myers, 2000), when epigean as well as hypogean forms where trapped in amber resin. These Cenozoic fossils closely resemble the living forms of today, and therefore would seem to point to a much older amphipod origin perhaps one more in line with other groups within the Peracarida such as the isopods, tanaids, cumaceans and spelaeogriphaceans. Fossils of these latter groups date back to the Carboniferous (Schram, 1981).

Why is it that no Paleozoic or Mesozoic fossils are found among the Amphipoda? The reason is probably twofold. Either no recognizable form existed, i.e., somehow the amphipods arose from relatively recent ancestors, or the amphipods living in the Mesozoic (or earlier) occurred in habitats that were quite unsuitable for fossilization. These latter ancestors could be deep sea, interstitial, and/or cave inhabitants. We assume that the colonization of the marine interstitial by small benthic crustaceans was an ancient event. A trend can be seen in the evolution of worm-like bodies in amphipods, which invaded older areas in ancient times and are present today in areas that have been emergent at least since the late Cretaceous. This stands in contrast to forms with rounder bodies, which resemble more their benthic relatives (Vonk, 1990; Coineau, 2000).

The present day ingolfiellideans that occupy underground waters far inland on the continents are the large cave lake inhabitants of Africa below the equator. Their counterpart, in body length and "micro-environmental requirements, is the one species of Metaingolfiella, known from a well in Italy. Returning to our original question of where to be- 


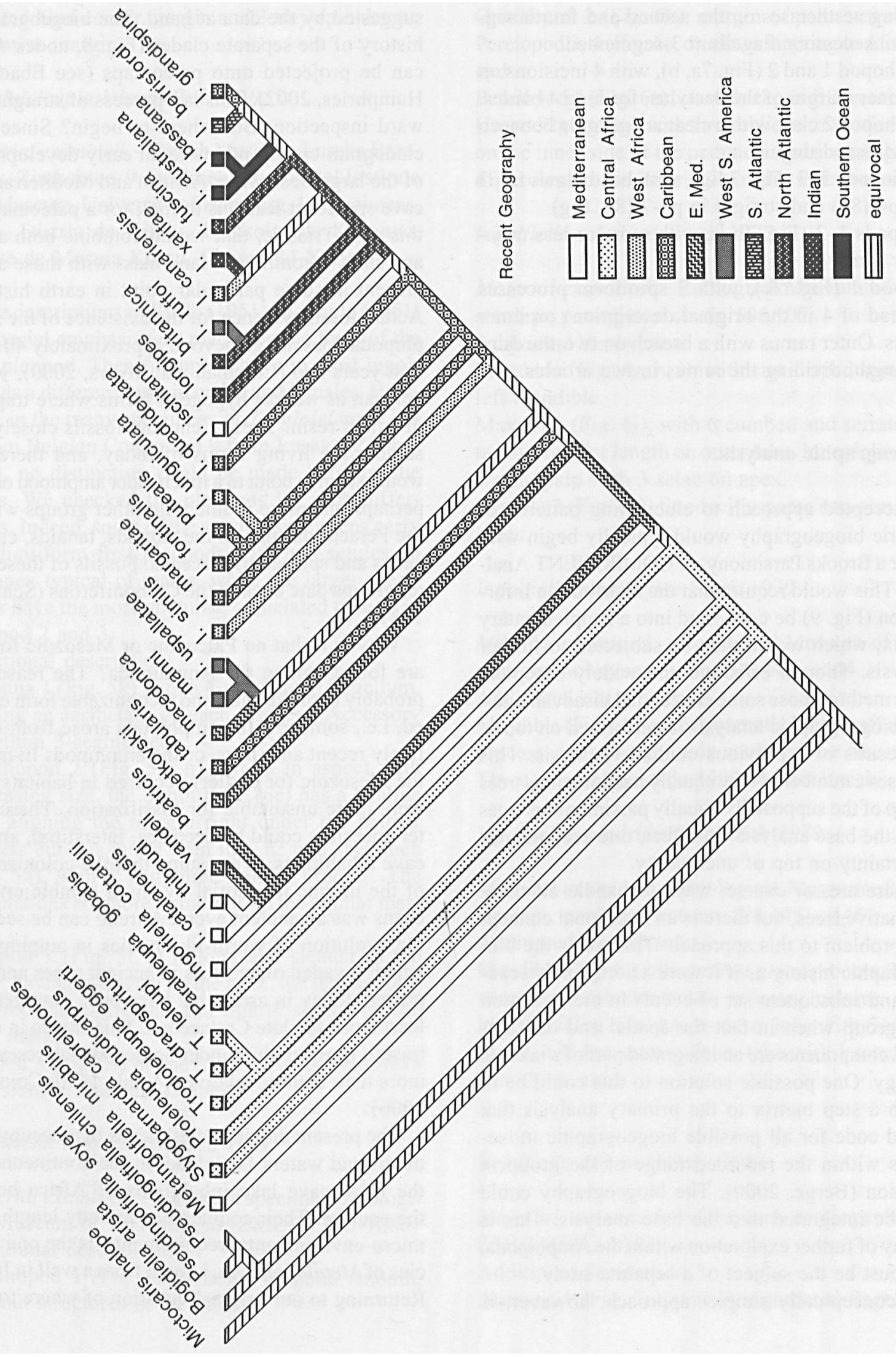

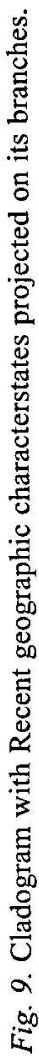


gin and project a common history on a paleomap, it seems justifiable to search for to a time where the African and Mediterranean freshwater forms could have had contact. The map from the Early Triassic (Scotese, 1977) reflects such a situation. The Pangaea and Gondwana geography of the Triassic can be fitted to the branches of those taxa that group together low in the clade of the ingolfiellideans (Fig, 10, Fig. 11A).

"Above" these stem taxa on the tree, we encounter species of Ingolfiella found today in groundwater habitats along the North Mediterranean coasts. As above, if we seek a period after the Triassic, we find in the Early Jurassic a time when the central Atlantic Ocean and western Mediterranean Sea was forming from the older West Tethys Ocean. We can plot the taxa that are found nowadays in the northern Mediterranean near-coastal areas onto the northern coast of the West Tethys Ocean in the Early Jurassic geography (Fig. 11B). There are exceptions, like Ingolfiella macedonica and especially $I$. ischitana that occur in this same geographic area but appear higher in the cladogram (Fig. 10).

In a similar manner, we find that the grade on the cladogram that represents the freshwater and brackish species from the present day Atlantic Islands and Caribbean area are easily projected paleogeographically onto the northern coast of Late Jurassic Gondwana (Fig. 12A).

The extremely high sea levels of the late Cretaceous and further opening of the Atlantic Ocean (Haq et al., 1987) could have seen an evolution and dispersal of marine benthic and infaunal elements linked with the expansion of coastlines and deep waterways. From the Cretaceous onward the spread of ingolfiellids over the earth might have taken place at a faster pace (Fig. 12B) into the North Atlantic and out over the unfolding Indo-Pacific.

\section{Discussion}

Our justification for interpreting paleomaps and looking for continuous landmasses that may have held vast underground bodies of freshwater through long periods of geological time, is congruent with the results of our analysis in which the species inhabiting the African Pre-Cambrian shield are pri- mitive forms. Such ìdeas have been formulated earlier (Ruffo, 1951; Leleup, 1955, Siewing, 1963), but Dahl (1977) remarks that a reduction of pleopods is unusual in species living in larger bodies of subterranean waters and thus he maintained that this feature must have been inherited from interstitial ancestors without fully developed pleopods. Therefore it is unlikely, according to Dahl, that these cave forms could have been ancestral to the smaller interstitial types. However, a detailed description of Leleup (1955) on the ecology of Trogloleleupia leleupi, a large cave-inhabiting ingolfiellidean from Congo, reveals that this species does not employ a free swimming behavior but rather moves across the bottom on its side. This suggests the true bottom dwelling nature of ingolfiellideans. Further speculations on whether small interstitial forms with reduced pleopods transformed back into larger cave forms with, secondarily derived, functionally active pleopods cannot be investigated any further without fossil forms.

A number of alternative evolutionary scenarios concerning ingolfiellidean origins now present themselves. First, a marine ancestor could have invaded the fresh-water underground environment in the Early Triassic, or even Late Paleozoic, with concomitant anatomical reductive adaptations taking place. In some cases, a "rebuilding" of reduced features (pleopods, third uropods) might have occurred especially when the infestation of the interstitial environment (with its confined spaces) was followed by radiation into cave-lake systems and underground rivers. Second, limno-stygobionts, as the large African inland species represent could have evolved into cave forms from surface water limnic ancestors. This phenomenon has been extensively studied in recent times by Culver et al. (1995) in the case of Gammarus minus. In the case of ingolfiellids, however, this route is unlikely because no epigean relatives are known to exist. Third, the peracarids may have been interstitial and/or groundwater forms in origin. This possibility has been little considered. In its favor, however, is the fact that the most primitive gammaroids (crangonyctids, bogidiellids) occupy such habitats. The spelaeogriphaceans also occur in caves, and Spears (pers. comm.) believes molecular evidence supports a common origin of spelaeogriphaceans and amphipods. In 


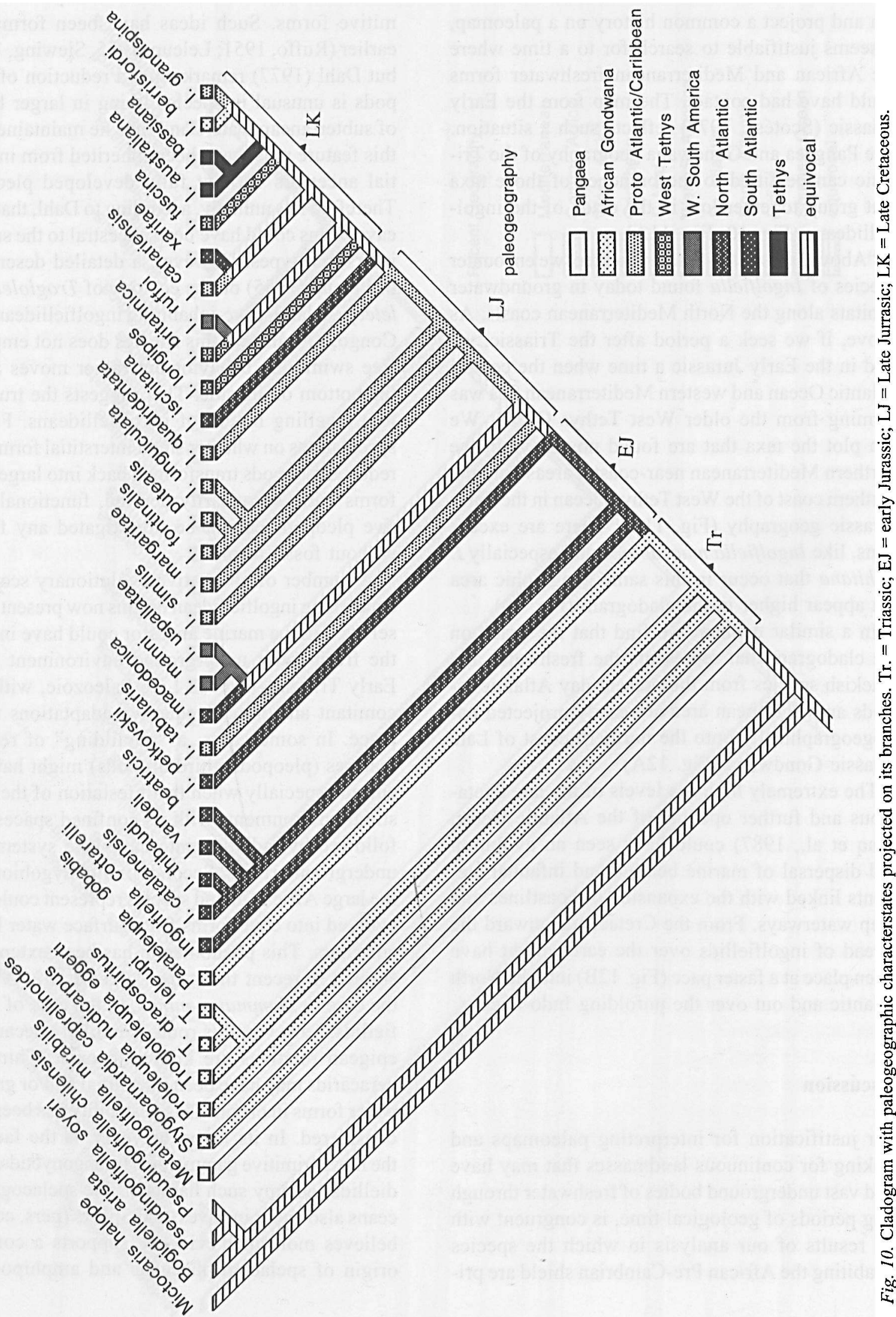



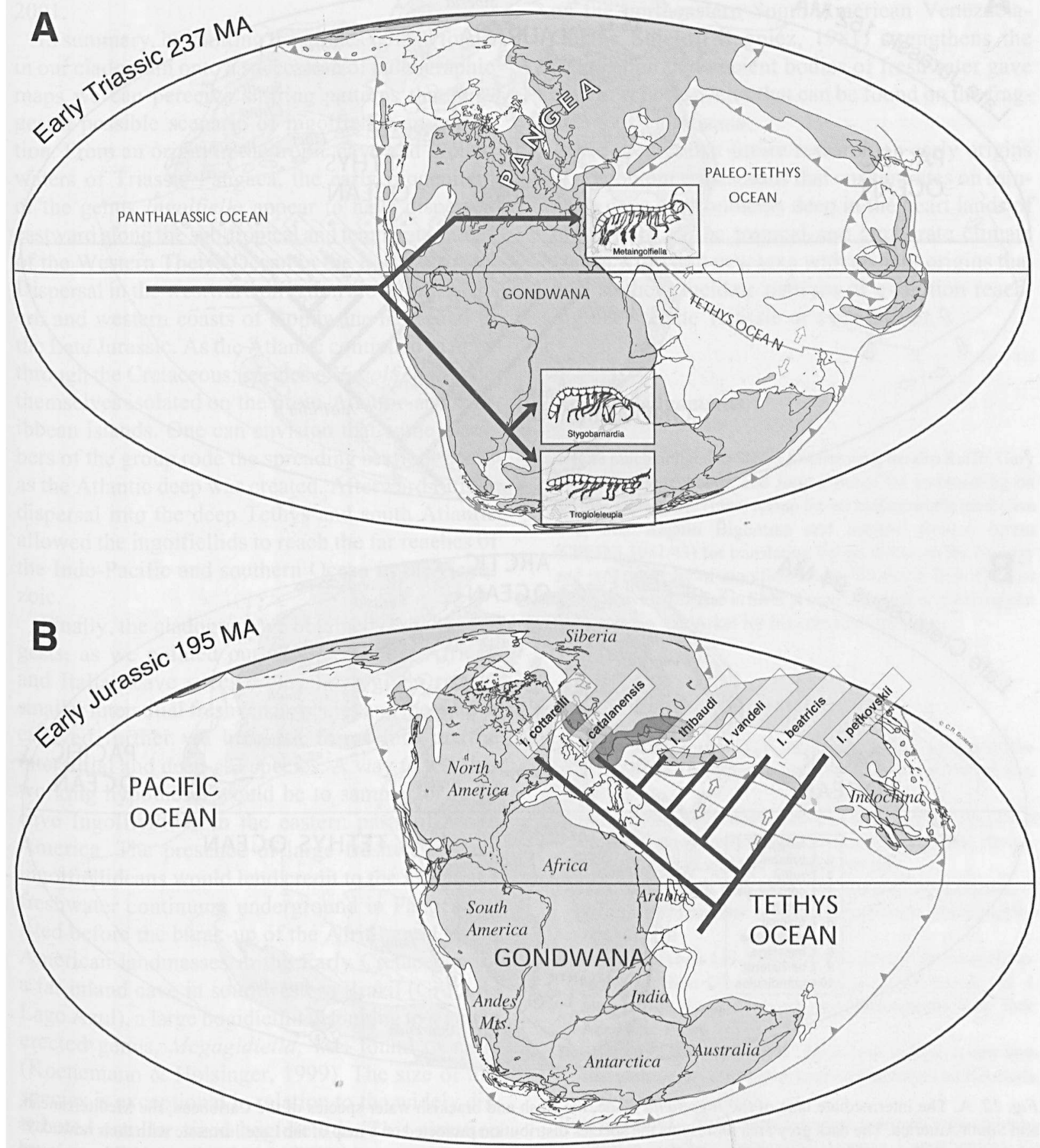

Fig. 11. Early parts of the phylogenetic tree projected on different epochs of geological history. A, three rectangles on the map of the Early Triassic represent roughly the distribution of the depicted taxa. B, The dark grey area on the map of the early Jurassic represents the area adjacent to the Recent mediterranean distribution of the eartiest evolved species of the Ingolfiella clade (see Fig. 8). Notice this distribution is continuous and restrained to a limited area (maps modified after Scotese, 1997). 

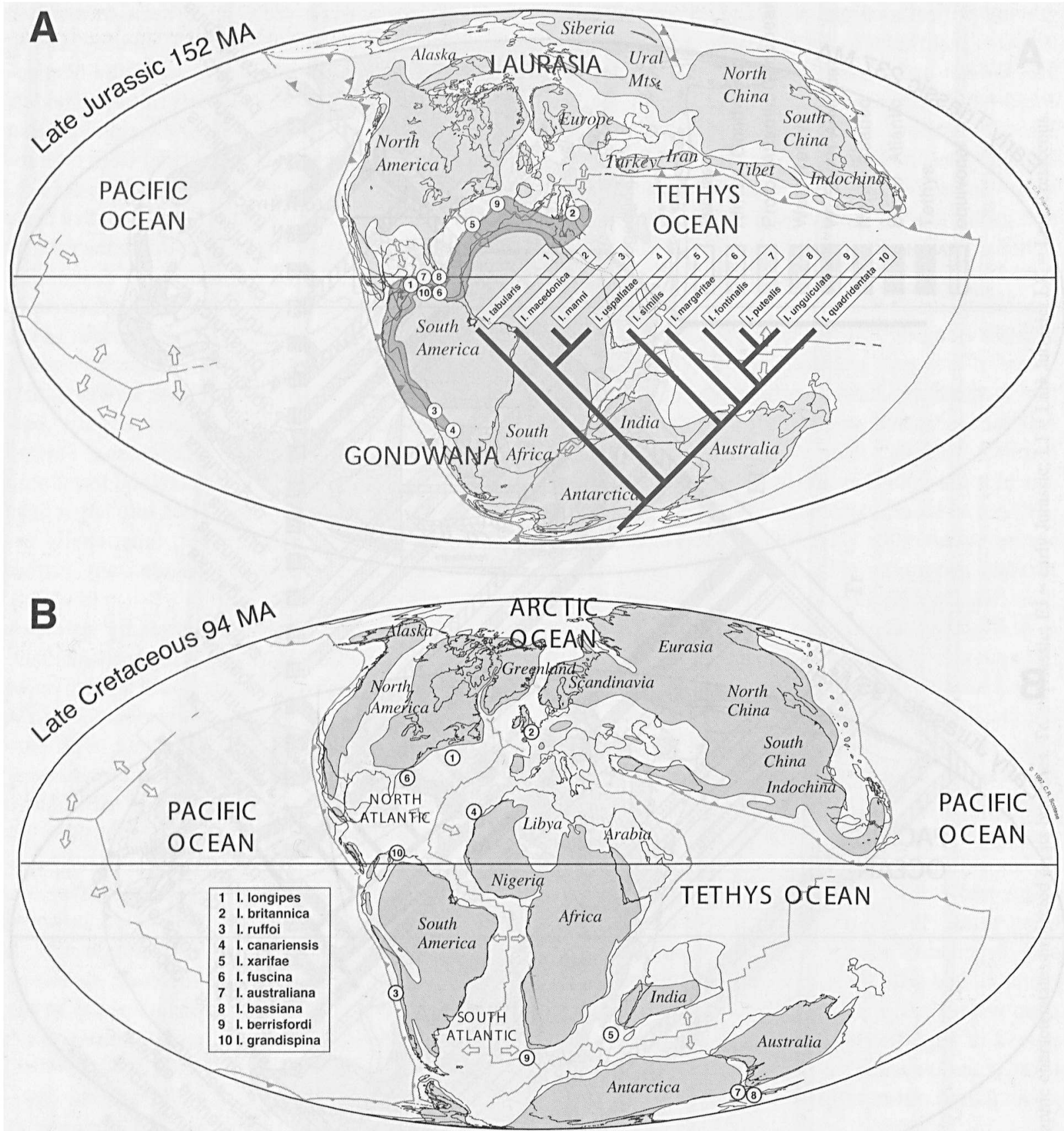

Fig. 12. A. The intermediate taxa of the Ingolfiella clade, the fresh and brackish water species of the Caribbean, the Mediterranean, and South America. The dark grey area represents the species distribution projected on a map of the Late Jurrassic with their nowadays occurrence. B. the most derived taxa of Ingolfiella containing marine species with a scattered distribution virtually worldwide, projected on a map of the Late Cretaceous (maps modified after Scotese, 1997).

addition, the most primitive isopods, the phreatoicids, occupy allied habitats (Wilson, 1998).

In contrast, much has been written as to how preadapted marine benthic crustaceans could pas- sively or actively invade the insular and continental ground water. Recent overviews (with numerous references to authors who have published on this subject) are presented by Holsinger, 2000; Coineau, 
2000; Stock, 1993; Humphreys, 1999; Botosaneanu, 2001.

In summary, by plotting the grades of taxa found in our cladogram onto a succession of paleographic maps we can perceive shifting patterns that suggest a possible scenario of ingolfiellidean evolution. From an origin in the tropic cave and ground waters of Triassic Pangaea, the early progenitors of the genus Ingolfiella appear to have dispersed eastward along the sub-tropical and temperate shores of the Western Thetys Ocean in the Early Jurrasic. Dispersal in the westward direction along the northern and western coasts of Gondwana happened in the Late Jurassic. As the Atlantic continued to open through the Cretaceous, species of Ingolfiella found themselves isolated on the proto-Atlantic and Caribbean islands. One can envision that some members of the group rode the spreading seafloor down as the Atlantic deep was created. Afterward further dispersal into the deep Tethys and south Atlantic allowed the ingolfiellids to reach the far reaches of the Indo-Pacific and southern Ocean in the Cenozoic.

Finally, the cladogram we obtained (Fig. 8) suggests, as we pointed out above, that the African and Italian cave species may have given rise to smaller interstitial freshwater species and these have evolved further via brackish forms into marine interstitial and deep-sea species. A way to test this working hypothesis would be to sample for large cave Ingolfiellidea in the eastern parts of South America. The presence of large freshwater cave ingolfiellideans would lend credit to the idea that a freshwater continuum underground in Pangea existed before the break-up of the African and South American landmasses in the Early Cretaceous. In a far inland cave in southwestern Brazil (Gruta do Lago Azul), a large bogidiellid belonging to a newly erected genus, Megagidiella, was found recently (Koenemann \& Holsinger, 1999). The size of this species is exceptional in relation to the widely distributed smaller sized bogidiellids. This situation is more or less comparable to what is seen in ingolfiellideans, i.e., large cave species far inland that are rare and found in places with 'relict' faunas, as opposed to the small species from the species-rich interstitial habitats closer to the sea. The strictly stygobiont freshwater isopod family Stenasellidae has a distribution that points to a Cretaceous ori- gin. Consequently, the occurrence of this family on the northeastern South American VenezuelaGuiana Shield (Magniez, 1981) strengthens the proposition that ancient bodies of freshwater gave rise to "relict' species that can be found on the fragments of Gondwana.

We predict that future research on early origins of stygobiont crustaceans that concentrates on sampling cave environments deep in the heart lands of old cratons in the tropical and temperate climate zones, will yield new taxa with ancient origins that will further elucidate patterns of evolution reaching back to the Triassic or even earlier.

\section{Acknowledgements}

We are much obliged to Stefan Koenemann, Sandro Ruffo, Gary Poore, Jos Notenboom, and Jørgen Berge for commenting on the manuscript, Dr. Traudl Krapp for her indispensable mediative role, and Angelo Bigontina and Simona Seveso (grant ICP94NL3041/43) for translating Italian works on the ecology and biogeography of ingolfiellideans. We thank Dirk Platvoet for his active assistance in SEM photography and original suggestions and Jan van Arkel for his computer imaging.

\section{References}

Barnard JL, Karaman GS. 1983. Australia as a major evolutionary centre for Amphipoda (Crustacea). Mem. Austr. Mus. 18: $45-61$.

Berge J. 2000. A taxonomic revision and cladistic analysis of the amphipod family Stegocephalidae (Crustacea: Peracarida). Dissertation, Univ Tromsø, Norway.

Bousfield EL, Shih CT. 1994. The phyletic classification of amphipod crustaceans: problems in resolution. Amphipacifica 1(3): 76-134

Bowman TE,Abele LG. 1982. Classification of the recent Crustacea. In: Bliss DE, ed. The biology of Crustacea, vol. 1 . Systematics, the fossil record and biogeography. New York: Academic Press, 1-319.

Bowman TE, Iliffe TM. 1985. Mictocaris halope, a new unusual peracaridan crustacean from marine caves on Bermuda. J. Crust. Biol. 5: 58-73.

Botosaneanu L. 2001. Morphological rudimentation and novelties in stygobitic Cirolanidae (Isopoda, Cymothoidea). Ve Milieu 51 (1-2): 37-54.

Coineau N. 1977. Le genre Pseudingolfiella aux Kerguelen. Extrait de CNFRA 42: 287-293.

Coineau N. 2000. Adaptations to groundwater life. In: Wilkens $\mathrm{H}, \mathrm{Culver}$ DC, Humphreys WF, eds. Ecosystems of the world 30* subterranean ecosystems. Elsevier, 189-210.

Coleman CO, Myers AA, 2000. New amphipoda from Baltic amber. Polsk. Arch. Hydrobiol. 47: 457-464. 
Culver DC, Kane TC, Fong DW. 1995. Adaptation and natural selection in caves. Cambridge: Harvard University Press, 1-223.

Dahl E. 1977. The amphipod functional model and its bearing upon systematics and phylogeny. Zool. Scripta 6: 221-228.

Ebach MC, Humphries CJ. 2002. Cladistic biogeography and the art of discovery. $J$ Biogeography 29: 427-444.

Hansen HJ. 1903. The Ingolfiellidae, fam, $n$, a new type of Amphipoda. J. Linn. Soc. (Zool.), London 29: 117-133, plates 14-15.

Haq BU, Hardenbol J, Vail PR. 1987. Chronology of fluctuating sea levels since the Triassic. ${ }^{\times}$Sclence 235: 1156-1167.

HoIsinger J. 2000. Ecological derivation, colonization, and speciation. In: Wilkens $\mathrm{H}$, Culver DC, Humphreys WF, eds. Ecosystems of the world 30: subterranean ecosystems. Elsevier: 399-416.

Humphreys WF. 1999. Relict stygofaunas living in sea salt, karst and calcrete habitats in arid northwetern australia contain many ancient lineages. In: Ponder W, Lunney D, eds. The other 99\%, the conservation and biodiversity of invertebrates. Tr. Roy, Zool, Soc. New South Wales, 219-227.

Just J, Poore G. 1988. Second record of Hirsutilidae (Peracarida: Mictacea): Hirsutia sandersetalia, new species, from Southeastern Australia. J. Crust. Biol. 8(3): 483-488.

Karaman SL. 1959. Ueber die Ingolfielliden Jugoslawiens. Bioloski Glasnik 12: 63-80

Koenemann S, Holsinger JR. 1999. Megagidiella azul a new genus and species of a cavernicolous amphipod crustacean (Bogidiellidae) from Brazil, with remarks on its biogeographic and phylogenetic relationships. Proc. Biol. Soc. Wash. 112: 572-580.

Koenemann S, Holsinger JR. 1999. Phylogenetic analysis of the amphipod crustacean family Bogidiellidae, s. lat., and revision of taxa above the species level. Crustaceana 72 (8): 781-816.

Koenemann S, Vonk R, Schram FR. 1998. Cladistic analysis of 37 mediterranean Bogidiellidae (Amphipoda), including Bogidiella arista n .sp. from Turkey. $J$. Crust. Biol. 18: 383-404.

Leleup N. 1955. A propos de l'archaisme et de l'écologie de I'Ingolfiella leleupi Ruffo. Notes Biospéologiques 10: 145148.

Lincoln RJ. 1979. British marine Amphipoda: Gammaridea, London: British Museum (Natural History).

Lowry JK, Poore G. 1989. First ingolfiellids from the southwest Pacific (Crustacea: Amphipoda) with a discussion of their systematics. Proc. Biol. Soc. Wash. 102 (4); 933-946.

Lowry JK, Springthorpe RT. 2001 onwards. Amphipoda: Families and Subfamiliés. Version 1: 1 September 2001. http:/ /crustacea.net

Maas A, Waloszek D. 2001. Larval development of Euphausia superba Dana, 1852 and a phylogenetic analysis of the Euphausiacea. Hydrobiologia 448: 143-169.

Magniez GJ. 1981. Biogeographical aǹd Paleobiogeographical problems in stenasellids (Crustacea Isopoda Asellota of underground waters). Int. J. Speleol. 11: 71-81.

Martin JW, Davis GE. 2001. An updated classification of the recent Crustacea. Science Series of the Nat. Hist. Mus. Los Angeles County, no. 39: 1-124.

Mills EL. 1967. Deep-sea Amphippoda from the western North Atlantic Basin I. Ingolfiellidea and an unusual new species in the gammaridean family Pardaliscidae, Can. J. Zool. 45: 347-355.

Noodt W. 1959. Estudios sobre crustaceos Chilenos de aguas subterraneas II. Nueva Ingolfiella de aguas subterraneas limnicas de las Lomas de Paposo en el Norte de Chile. Invest. Zool. Chilenas 7: 7-16.

Noodt W. 1965. Interstitielle Amphipoden der konvergenten Gattungen Ingolfiella Hansen und Pseudingolfiella $\mathbf{n}$. gen. aus Sudamerika. Crustaceana 9: 17-30.

Richter S, Scholtz G. 2001. Phylogenetic analysis of the Malacostraca (Crustacea). J. Zool. Syst Evol. Research 39: 113-136.

Ruffo S. 1951. Ingolfiella leleupi $\mathrm{n}$. sp. nuovo anfipodo troglobio del Congo Belga. Rev. Zool. Bot. Afr. 44: 189-209.

Ruffo S. 1964. Studî suì crostacei anfípodi LVII: Un nuovo ingolfiellide delle acque sotteranee dell'Africa di Sud Ovest. Boll. Zool. 31: 1019-1034.

Ruffo S. 1969. Studí sui crostacei anfipodi LXIII: Descrizione dî Metaingolfiella mirabilis n. gen. n. sp. (Crustacea, Amphípoda, Metaíngolfiellidae fam. nova) delle acque sotterranee del Salento nell'Italia meridionale. Mem. Mus. Clv. Stor. Nat., Verona. 16: 239-260.

Ruffo S. 1970. Considérations à propos de la systématique et de la biogéographie de Ingolfielles (Crustacea Amphipoda). Livre centenaire Emile G. Racovitza, 223-230.

Schram FR. 1981. Late Paleozoic crustacean communities. $J$. Paleo. 55: 126-137.

Scotese CR. 1997. Paleogeographic atlas, Paleomap progress report 90-0497, Department of Geology, Univ. Texas Arlington, 1-37.

Shokita S. 1992 Aquatic animals of the Shiokawa salty spring. Motobu Museum Bulletin, Okinawa 6: 21-44

Siewing R. 1963. Zur Morphologie der aberranten Amphipodengruppe Ingolfiellidae und zur Bedeutung extremer Kleinformen für die Phylogenie. Zool. Anz. 171: 76-91.

Stock JH. 1976. A new member of the crustacean suborder Ingolfiellidea from Bonaire, with a review of the entire suborder. Stud. Fauna Curaçao 50: 56-75.

Stock JH. 1993. Some remarkable distribution patterns in stygobiont Amphípoda. J. Nat. Hist. 23: 807-819.

Takeuchi I, Ishimaru SI. 1991. Redescription of Caprogammarus gurjanovae Kudrjasehov \& Vassilenko, 1966 (Crustacea: Amphipoda) from Hokkaido, Japan, with notes on the taxonomic status of Caprogammarus. Hydrobiologia 223: 283-291.

Vonk R. 1990. Thalassostygius exiguus n.g., n.sp., a new marine interstitial melitid (Crustacea, Amphipoda) from Curaçao and Klein Bonaire (Netherlands Antilles). Stygologia 5: 43-48.

Vonk R, Sánchez E. 1991. A new marine interstitial ingolffielld (Crustacea, Amphipoda, Ingolfiellidea) from Tenerife and Hièrro. Hydrobiol. 223: 293-299.

Wilson GDF, 1998. Historical influences on deep-sea isopod diversity in the Atlantic Ocean. In: Smith CR., Mullineaux LS, Levin LA, eds. Deep-Sea Research Part II, Topical Studies in Oceanography 45(1-3), "Deep-sea biodiversity: a compulanon of recent advances in honor of Robert R. Hessler". Oxford, UK: Pergamon Press, 279-301.

Received: 2 September 2002 